Please do not remove this page

RMIT

UNIVERSITY

\title{
The changing trends of corporate social and environmental disclosure within the Australian gambling industry
}

Loh, Chin Moi; Deegan, Craig; Inglis, Robert

https://researchrepository.rmit.edu.au/esploro/outputs/9921859887601341/filesAndLinks?institution=61RMIT_INST\&index=null

Loh, C. M., Deegan, C., \& Inglis, R. (2015). The changing trends of corporate social and environmental disclosure within the Australian gambling industry. Accounting and Finance, 55(3), 783-823.

https://doi.org/10.1111/acfi.12075

Document Version: Accepted Manuscript

Published Version: https://doi.org/10.1111/acfi.12075

Repository homepage: https://researchrepository.rmit.edu.au

(C) 2014 AFAANZ

Downloaded On 2023/04/26 22:15:53 +1000

Please do not remove this page 
Thank you for downloading this document from the RMIT Research Repository.

The RMIT Research Repository is an open access database showcasing the research outputs of RMIT University researchers.

RMIT Research Repository: http://researchbank.rmit.edu.au/

\section{Citation:}

Loh, C, Deegan, C and Inglis, R 2014, 'The changing trends of corporate social and environmental disclosure within the Australian gambling industry', Accounting and Finance, pp. 1-41.

See this record in the RMIT Research Repository at:

https://researchbank.rmit.edu.au/view/rmit:28141

Version: Accepted Manuscript

Copyright Statement: (c) 2014 AFAANZ

Link to Published Version:

http://dx.doi.org/10.1111/acfi.12075 
This is the accepted version of the following article:

Loh, C, Deegan, C and Inglis, R 2014, 'The changing trends of corporate social and environmental disclosure within the Australian gambling industry', Accounting and Finance, pp. 1-41

which has been published in final form at http://dx.doi.org/10.1111/acfi.12075 


\title{
The changing trends of corporate social and environmental disclosure within the Australian gambling industry
}

\begin{abstract}
This study examines how the corporate social and environmental disclosure (CSD) practices of a sample of gambling companies operating within Australia appears to change around the time of three specific interrelated Australian government initiatives; the Productivity Commission, 1999, Australia's Gambling Industries, Report No.10, the subsequent establishment of the Ministerial Council on Gambling, and the MCG-initiated National Framework on Problem Gambling. Drawing upon three complementary theories, namely legitimacy, stakeholder and institutional theory, our analysis of the extent and type of CSD in the annual reports of gambling companies over a fifteen year period suggests that CSD is a response to social pressures created around the time of these initiatives.
\end{abstract}




\section{Introduction}

The last two decades have given rise to a burgeoning theoretical and empirical literature on the corporate social and environmental disclosure (CSD) practices of organisations in industries such as mining, garment manufacturing, and chemicals (Islam \& Deegan, 2008; Deegan \& Blomquist, 2006; O’Donovan, 2002; Milne \& Patten, 2002). There is, however, relatively limited research on the CSD practices of organisations in the gambling industry, and where such research has been undertaken, it does not appear to have been undertaken within the Australian context (for overseas research see Jones et al., 2009).

Australia has a long history of gambling and the industry has evolved to be one of significant national economic importance. It contributes 1.5 per cent of gross domestic product (Australasian Gaming Council, 2008), generates gambling taxes of around 10 per cent of state/territory tax revenues, and provides approximately 67,000 jobs (Productivity Commission, 2009). The economic benefits of gambling, however, come with substantial negative social costs. In particular, the habits of problem gamblers ${ }^{1}$ have been associated with various social issues, including family problems, crime, suicides, depression, relationship breakdowns, bankruptcy, and job loss (Productivity Commission, 1999).

This study examines CSD in the context of these social costs. Specifically, this study uses three interrelated Australian government initiatives (initiatives which are arguably reflective, or a manifestation, of community pressure) as proxies for public concerns about the social costs of gambling. These are: (1) the recommendations of the Productivity Commission, 1999, Australia's Gambling Industries, Report No. 10 (hereafter, referred to as PC1999), (2) the establishment of the Ministerial Council on Gambling (MCG), and (3) the MCG-initiated National Framework on Problem Gambling (NFPG). PC1999 was the first Australian government report produced from an independent national inquiry into the gambling industry in 1998. This inquiry attracted substantial public attention and PC1999 reflected an assimilation of community expectations and concerns. The MCG was established in 2000, and the NFPG implemented for the 2004-2008 period; both were a consequence of the recommendations from PC1999.

Drawing upon legitimacy, stakeholder, and institutional theory, we propose that changes in the CSD of gambling organisations coincide with specific community concerns and pressure that were reflected in PC1999's recommendations, the formation and operation of the MCG, and the establishment of the NFPG. In this study, we examine the extent and type of CSD found in the annual reports of two major publicly-listed, and highly visible Australian gambling organisations: Crown Limited and Tabcorp Holdings Limited (referred to hereafter as Crown and Tabcorp, respectively). Our research covers the fifteen-year period from 1995 to 2009.

\footnotetext{
${ }^{1}$ In Australia, people seeking help from counselling agencies for their gambling are labelled as 'problem gamblers'. The South Oaks Gambling Screen (SOGS) is a set of questions used to determine whether a person is a problem gambler (Australian Gambling Industries, 1999). Those scoring 10 or higher on the SOGS can be labelled as 'problem gamblers'; those scoring 5 to 9 are often described as 'at-risk'.
} 
We undertook our research because we are interested in understanding the nature of the CSD practices of Australian gambling organisations. In doing so, we address an apparent void in the social and environmental accounting literature. Because the gambling industry does create a multitude of highly publicised social impacts, both positive and negative, we are interested in understanding the extent to which gambling organisations publicly disclose information about their contribution to such impacts, together with any information about actions they might undertake to alleviate problems associated with issues such as problem gambling. We are particularly interested in understanding the focus areas of the organisations' CSD and the potential motivations for any such disclosure. Such evidence, which is not currently available within the Australian context, is of direct relevance to researchers, and others, interested in the extent to which Australian gambling companies disclose information about the social impacts of their operations.

As we will show within this paper, rather than perhaps being driven by a desire to provide an objective account of the non-financial consequences of their activities, our research shows that our sample of organisations from the gambling industry appear to utilise public disclosures in a manner consistent with an intent to legitimise their activities at a time when such activities had come under particular political scrutiny. The social and environmental disclosures made by our sample organisations appears to change as the political scrutiny focused upon the gambling industry changes. Specifically, the disclosures appear consistent with a perspective that the companies are using their disclosures for the purpose of legitimation rather than as a means of objectively providing an account of the social aspects, or impacts, of their operations. Further, whilst community concern in relation to problem gambling appeared to heighten during the period of our investigation, our sample companies provided relatively little disclosure in relation to problem gambling (albeit, it did increase across the period of our analysis) when compared to disclosures relating to issues such as community involvement and human resources. That is, it appeared that they were deflecting attention from problem gambling - the issue at the forefront of political attention - to other social and environmental issues.

Another result from our study indicates that the level of CSD fell across all of our categories of disclosure around the time of the global financial crisis when arguably the organisations believed it was more important to concentrate upon making disclosures that primarily focused upon those parties with a financial interest in the organisations.

The results of our research not only provide insights into what is motivating the disclosure, but by highlighting the apparent strategic nature of the disclosures, our research could provide the basis for questions about the possible need to regulate disclosures made by organisations operating within the Australian gambling industry.

This balance of the paper is organised as follows: Section 2 provides a brief overview of the Australian gambling industry; Section 3 reviews the three Australian government initiatives (i.e., 
PC1999, MCG, and NFPG) ${ }^{2}$; Section 4 examines three interrelated theories (legitimacy, stakeholder, and institutional theory) that are frequently used in social and environmental accounting research, and which underpin our study; and Section 5 describes the research method, including a brief discussion of the two gambling organisations comprising our sample (Crown and Tabcorp). Section 6 presents the results of our CSD analysis of the annual reports in the periods before and after the three government initiatives. In Section 7 we discuss our findings and provide concluding comments followed by a brief discussion of potential future research.

\section{The Australian gambling industry}

Gambling is an old industry and also one of the most profitable and fastest growing industries globally. Gambling has been defined as "entertainment based on staking money on uncertain events driven by chance, with the potential to win more than staked, but with the ultimate certainty that gamblers as a group will lose over time” (Productivity Commission, 2010). While there are many different forms of gambling activity in Australia, the principal forms are gaming and wagering. Gaming comprises all legal forms of gambling other than wagering and includes lotteries, gaming machines $^{3}$, casino table games, and keno; wagering is betting on the outcome of any uncertain event with the major forms being racing and sports betting. Consequently, the 'gambling industry' is defined as an industry inclusive of organisations that provide any of these principal forms of gambling services. Such organisations include casinos, clubs, hotels, Totalisator Agency Boards (TABs), sports betting enterprises, and lottery organisations (Productivity Commission, 1999).

Since the first official wager on a horse race held in 1810, Australia's gambling industry has grown to a total of thirteen casinos (with at least one casino in each state/territory), almost 200,000 electronic gaming machines (EGMs) in operation (including EGMs in casinos, hotels, and clubs), and ubiquitous lottery products (Productivity Commission, 2009). The gambling industry in Australia employs around 67,000 people directly; an additional 105,000 are employed indirectly in related jobs (such as those employed in hotels and clubs), with around 50,000 jobs in the racing industry (Productivity Commission, 2009). According to the Australasian Gaming Council ${ }^{4}$, it is estimated that there are around 15,000 businesses providing gambling services in Australia, with numerous allied industries such as tourism, leisure, retailing, and other entertainment.

\footnotetext{
${ }^{2}$ The Australian Government conducted the latest public inquiry into the gambling industry in 2008 and its report was released in June 2010: Gambling - Inquiry Report, 2010. The latest report did not form part of this current study as annual report information was not available at the time.

${ }^{3}$ Gaming machines are also referred to as electronic gaming machines (EGMs), poker machines, pokies or slot machines (Productivity Commission, 1999).

${ }^{4}$ The Australian Gaming Council (AGC) is a national body established by the gambling industry in June 2000. It claims to support a sustainable gambling industry that provides entertainment and economic benefits while promoting gambling education and responsible gambling measures. AGC's members come from all sectors of the industry - wagering, licensed operators, clubs, hotels, and casinos. In November 2007, the Australian Gaming Council changed its name to the Australasian Gaming Council to encompass New Zealand memberships (http://www.austgamingcouncil.org.au).
} 
Gambling provides a substantial source of profits and taxes for gambling companies (and therefore, dividends for shareholders) and state/territory governments, respectively. These substantial profits have encouraged the strong expansion of the gambling industry. In Australia, gambling consumption expenditure ${ }^{5}$ increased from AUD\$11 billion in 1997-98 (Productivity Commission, 1999) to AUD\$19 billion in 2008-09, which was about the same as alcohol sales in Australia (Productivity Commission, 2010). The gambling industry contributes tax revenues of at least AUD $\$ 4.7$ billion annually, which represents approximately 10 per cent of state/territory taxation revenue (Australian Bureau of Statistics, 2006/07). Therefore, the contribution to the total tax revenues of government is significant.

The liberalisation of gambling in the 1990s contributed substantial economic benefits to Australia in terms of contributions to taxes, associated tourism, employment and the like; however, the growth of the gambling industry has also raised community concerns about the adverse social impacts upon many Australians and their families, particularly the issue of problem gambling ${ }^{6}$. Responding to growing community concerns, in 1998 the Australian Government conducted its first independent national inquiry into the gambling industry, with the aim of enhancing public and industry understanding of industry-related issues, and particularly its economic and social impacts. We will now consider government initiatives raised to address some of the social issues associated with gambling.

\section{Australian Government initiatives}

\subsection{The Productivity Commission’s inquiry 1999}

Public concern about the adverse social impacts of gambling was the impetus for the Australian Government's first independent national inquiry into the gambling industry. In August 1998, the Federal Treasurer of Australia requested that the Productivity Commission generate a report on the economic and social impacts of gambling, and the effects of the different regulatory structures that surrounded gambling and related industries. Although the terms of reference did not suggest any formal policy recommendations, it provided a range of policy-relevant findings to assist government decision-making (Productivity Commission, 1999).

The inquiry obtained views from many diverse interests and attracted considerable public attention, resulting in a total of 290 submissions $^{7}$, including approximately 29 per cent from welfare and community organisations, 21 per cent from individuals, 18 per cent from government agencies (including local government), and 19 per cent from gambling providers (Productivity Commission, 1999).

\footnotetext{
${ }^{5}$ Expenditure is the net amount lost by gamblers (the amount staked by gamblers, minus their winnings). This is the same as the gross profit of the gambling operator (Australia's Gambling Industries, 1999).

${ }^{6}$ Problem gambling is characterised by difficulties in limiting money and/or time spent on gambling which leads to adverse consequences for the gambler, others, or for the community (Neal et al., 2005)

7 The 290 public submissions are accessible at the Productivity Commission webpage: www.pc.gov.au/projects/inquiry/gambling/docs.submissions.
} 
The Productivity Commission inquiry involved extensive nation-wide research with those closely interested in, affected by, or that provided or used gambling products. Research included six formal roundtable discussions, three national surveys: a 'National Gambling Survey' (the survey investigated gambling preferences, spending, attitudes, and impacts); a 'Survey of Clients of Counselling Agencies' (the survey produced a profile of problem gamblers); and a 'Survey of Counselling Services' (the survey explored funding, caseloads, methods of approach, and outcomes) (Productivity Commission, 1999). Public hearings were conducted in all capital cities for interested parties to discuss their submissions with the Commissioners during November and December 1998, followed by a final round of public hearings that were held in major cities after the release of a draft report in July 1999. The final report, PC1999, was released in December 1999.

PC1999 and its recommendations resulted from high levels of community engagement with a wide range of participants who raised various concerns with, and expectations of, the gambling industry in terms of the social costs, in particular, those associated with problem gamblers. In this study, we use PC1999 and its recommendations in particular, as a proxy for community concerns. As we will explain, the publication of the PC1999 brought many negative issues associated with the gambling industry into public focus and there would be an expectation that this scrutiny would evoke some form of disclosure response from affected organisations - that is, from the gambling organisations. We will explain the basis for this explanation shortly.

\subsection{The Ministerial Council on Gambling (MCG) and its National Framework on Problem Gambling (NFPG)}

Following the release of PC1999, the Australian government adopted the key recommendation of PC1999 and the Council of Australian Governments (COAG) and formally established a Ministerial Council on Gambling (MCG) in April 2000. Then Prime Minister, John Howard, committed the Commonwealth Government to a leadership role, and the establishment of the MCG aimed to achieve a national approach to the challenges of problem gambling (http://www.gamblingresearch.org.au). The objective of the MCG was to minimise the negative social impacts of problem gambling by exchanging information on responsible gambling strategies and discussing common issues to facilitate the development of suitable regulatory approaches. The MCG's membership consisted of Ministers with responsibility for gambling in each state/territory. In developing a national approach to tackling problem gambling, the MCG considered various issues, particularly the PC1999 recommendations (www.gamblingresearch.org.au).

In 2003, the MCG developed a National Framework on Problem Gambling 2004-2008 (NFPG) with a priority on 'public awareness, education and training', the establishment of a 'responsible gambling environment', 'intervention, counselling and support services', and 'national research and data collection'. The focus of the NFPG was to minimise harm associated with problem gambling as recommended in PC1999. The recommendations of PC1999 and the subsequent focus of the NFPG are 
shown in Table 1. Within Table 1 we have attempted to align the recommendations of PC 1999 (column 1) with the priority areas subsequently established for the NFPG (column 2). In the last two MCG meetings in 2008 and 2009, the emphasis was on the development of a national work program to tackle problem gambling. The program was to build on a number of principles in the NFPG 2004-2008 that addressed risks associated with gambling, including: 'harm minimisation measures', 'responsibility for minimising harm associated with problem gambling'; 'collaborative partnerships in implementing harm minimisation measures', and 'research and evaluation of harm minimisation'.

\section{Insert Table 1 here}

In summary, through the establishment of the NFPG, the aim of the MCG was to alleviate the negative social impacts of problem gambling by recommending to the Australian State and Territory governments various harm minimisation approaches and ways to promote a responsible gambling environment as identified in PC1999. The formation of the MCG, and more specifically the NFPG, reflects community expectations for organisations that provide any, or all, of the principal forms of gambling services. Whether these government initiatives, which were driven by community pressure, have resulted in a change in CSD practices of organisations operating within the Australian gambling industry is the focus of our research. CSD in media such as annual reports are voluntary and hence management has discretion about what types of disclosures, if any, to make ${ }^{8}$. As we shall soon explain, our view will be that the establishment of the MCG and subsequently the NFPG further sustained and increased the pressure on the gambling industry over and above that which was already created by PC1999. This would provide further impetus for organisations to make public disclosures to counter the increasing pressures that were being faced (perhaps by deflecting attention to more positive social impacts being generated by the organisations).

\section{Theoretical background and development of propositions}

Three complementary theories - legitimacy, stakeholder, and institutional theory - have been widely used in CSD research (Chen and Roberts 2010) ${ }^{9}$. In this study, we draw upon these theories to predict and explain the potential disclosures of gambling organisations in response to Australian government initiatives (PC1999 and the MCG’s NFPG).

Legitimacy theory is one of the most widely used theories to explain management motivations for CSD (for comprehensive accounts see, for example, Deegan, 2002; Deegan, 2014; Gray et al., 1996; and Mathews, 1993). Suchman (1995, p.574) states that "[l]egitimacy is a generalised perception or

\footnotetext{
${ }^{8}$ As Deegan (2013) explains, CSD is generally not required by International Financial Reporting Standards, ASX Listing Requirements, or the Corporations Act. Rather, these sources of regulation tend to fixate on providing information pertaining to the financial performance and position of a reporting entity, thereby leaving as predominantly voluntary the choice to disclose social and environmental information.

As Gray et al (2006) explain, these theories have their origins in another theory known as 'political economy theory'. The 'political economy' has been defined by Gray et al (1996, p.47) as "the social, political and economic framework within which human life takes place".
} 
assumption that the actions of an entity are desirable, proper, or appropriate within some socially constructed system of norms, values, beliefs and definitions”. Legitimacy theorists often rely upon the notion of a 'social contract' and the assumption that organisations will adopt various legitimation ${ }^{10}$ tools - including disclosure - to inform the general public that the organisation is attempting to comply with societal expectations, and therefore, to comply with the social contract. The 'social contract' or 'license to operate' is considered to represent an implicit agreement between an organisation and its society (Shocker and Sethi, 1974). That is, legitimacy is a conferred status that is controlled by others and grants rights to organisations' to operate. Nevertheless, societal expectations are not static but evolve over time. To maintain legitimacy, organisations must be responsive to changes in public expectations (Lindblom, 1993). Chen and Roberts (2010) consider legitimacy theory as an overarching theory reflecting broader societal-level views from which the relationships with institutional, resource and stakeholder theory can be observed.

In the late 1990s, the issue of problem gambling and its adverse social impacts on many Australians and their families shifted community concerns to the social costs of gambling rather than its economic benefits (Productivity Commission, 1999). According to the findings of PC1999, around 70 per cent of Australians considered that gambling did more harm than good, and the degree of concern appeared to be increasing across time. It was the increasing community concern about problem gambling that motivated the government to commence its various initiatives to address problem gambling-related social issues (Productivity Commission, 1999). The findings of the PC1999 indicated that the community concerns about gambling's economic and social impacts had heightened. Issues associated with problem gambling were potentially creating legitimacy threats for the industry with the consequential result that government might react to the community concern (through, for example, restrictive regulation, introduction of additional taxes, and so forth).

As Deegan et al. (2002, p.319) argue, "when significant events such as a major environmental disaster occur, or when there is sustained mass media interest, then it is reasonable to assume that most managers would perceive that the organisation's ongoing legitimacy is threatened”. The significance of the findings documented in PC1999 was evident in the response by the gambling industry, which expressed strong concerns over the potential negative public reaction to the draft report of PC1999, given its heavily focused statements about problem gambling and the related social costs of gambling. For example, in a submission to the Productivity Commission, Tabcorp expressed the view that the draft report of PC1999 lacked balance and was "damaging to the industry” (Productivity Commission, Submission: D232, p. 3). The view from organisations such as Tabcorp that the draft report was significant enough to cause 'damage' would conceivably motivate managers to adopt strategies, including disclosure strategies, to counter the possible damage. That is, "threats” to an organisation's perceived legitimacy lead to responsive actions by management, who will endeavour to minimise the

${ }^{10}$ Lindblom (1993) distinguishes between legitimacy and legitimation where the first is a status or condition and the latter is the process of obtaining the status or condition. 
impacts of such threats ${ }^{11}$. Prior research on CSD suggests that organisations will use CSD as a tool to respond to perceived threats to their organisational legitimacy ${ }^{12}$ (Deegan et al., 2000; Deegan \& Rankin, 1997; Patten, 1992). The annual report is one form of reporting or disclosure that is considered a vehicle for shifting community perceptions back in favour of the organisation (O’Donovan, 2002). Gray et al. (1995a, p.54) maintain that the annual report is not only a statutory document, but also an “important document in terms of the organisation's construction of its own social imagery".

Given the focus of PC1999 on aspects of problem gambling and the promotion of responsible gambling, we anticipate a subsequent increase in annual report disclosures about the positive social aspects of gambling organisation (for example, support of community initiatives, local sporting events and clubs, tax contributions), and about the initiatives being implemented to address the negative aspects of gambling. Based on the above, the first proposition of this study is that:

P1: There will be an increase in the extent of CSD by gambling organisations in their annual reports (particularly in the responsible gambling category) following PC1999.

Stakeholder theory is often utilised by researchers (in conjunction with legitimacy theory) to explain motivations for CSD. Stakeholder theory holds that organisations are not only accountable to their shareholders, but also to their stakeholders ${ }^{13}$. According to O’Donovan (2002), many CSD studies moved away from a focus on legitimating to 'society', towards legitimating to 'stakeholders' (or, as they are sometimes referred, the "conferring publics”).

Deegan (2014) explains that 'stakeholder theory' is a broad 'umbrella term' for a number of related theoretical perspectives that place the 'stakeholder' as a key focus of analysis. Stakeholder theories can be subdivided into two broad branches; these being the ethical branch and the managerial branch of stakeholder theory (see Deegan, 2014, pp. 371 to 382 for more detail). The ethical branch is based on various moral reasonings and is normative in nature as it prescribes how organisations should interact with, or treat, their stakeholders. Conversely, the managerial branch is positive in nature and tends to

\footnotetext{
${ }^{11}$ According to Lindblom (1993), there are four courses of action that an organisation can take to obtain, maintain or regain legitimacy following legitimacy threatening events: (i) educate and inform its "relevant publics" about (actual) changes in the organisation's performance and activities; (ii) change the perceptions of the "relevant publics" but not change its actual behaviour; (iii) manipulate perceptions by deflecting attention from the issue of concern to other related issues that have community appeal or acceptance; or (iv) change external expectations of its performance by possibly demonstrating that specific societal expectations are unreasonable. Central to all of these strategies is the public disclosure of (legitimising) information.

${ }^{12}$ There are two major aspects of legitimating behaviour. Some legitimating behaviour is aimed at legitimising the position of an organisation within a given social or institutional setting, whilst other legitimating behaviour may be focused upon legitimising broader social or institutional structures operating within society. In practice it is often difficult to differentiate between the two (Gray et al., 1996; Suchman, 1995).

${ }^{13}$ Stakeholders are often considered as those individuals or parties that have interests that affect, or are affected by, the actions of the firm (Freeman, 1984) and this includes customers, employees, suppliers, governments, and not-for-profit organisations (McWilliams \& Siegel, 2001).
} 
provide explanations or predictions for why managers might behave in particular ways, for example, why they might elect to disclose particular information.

Pursuant to the managerial branch of stakeholder theory, the importance of a stakeholder depends on the influence or control they possess over "resources" required by the organisation. The more powerful the stakeholder is in terms of controlling organisational resources, the more effort is taken to meet their expectations and demands. Gray et al. (1996) maintain that information is a major element that can be employed by the organisation to manage (or manipulate) the stakeholder in order to gain their support and approval, or to distract their opposition and disapproval. In this case, the annual report is a medium through which information about particular social or environmental issues/activities of the organisation can be conveyed to powerful stakeholders in an effort to affect their actions in a manner that is beneficial to the organisation (Deegan et al., 2002; Deegan \& Blomquist 2006). Thus, stakeholder theory offers a rich understanding on how organisations can strategically manage their particular powerful stakeholders (Neu et al., 1998; Ullmann, 1985) and balance the often conflicting demands of different stakeholder groups (Chen and Roberts, 2010).

In our study, the 'community' may be perceived as a 'powerful' stakeholder in the gambling industry, given its power to influence government initiatives and decisions (such as PC1999) that may then have further impact on the operations and future of gambling organisations. Without community pressures, there might be no social responsibility-related initiatives established by gambling companies and governments in view of the attractive gambling profits and tax revenues for companies and government respectively. In the event that gambling organisations are able to meet, or satisfy, the powerful stakeholders' ('community') expectations then this could mean that there might be no intervening initiatives from governments (such as PC1999, the MCG and NFPG), and no further introduction of regulations for gambling. ${ }^{14}$ Accordingly, gambling companies may feel driven to respond to the social expectations and concerns of the community as they are reflected in the MCG's harm minimisation initiatives or, more specifically, the NFPG. The response by gambling companies could be a strategy to alleviate and/or influence community concerns and prevent or mitigate the effects of potentially onerous regulations and policies that may impact on the operational practices and profitability of gambling organisations. From a stakeholder theory perspective, two propositions are advanced. The first is that:

P2a:Following the release of the MCG's National Framework on Problem Gambling 2004-2008 there will be a further increase (over and above that caused by the PC1999) in the extent of

\footnotetext{
${ }^{14}$ As an example of the introduction of legislation in response to particular concerns, the New South Wales's Gaming Machine Act 2001 (for hotels and clubs) was introduced to foster responsible gambling and minimise problem gambling. More recently, the National Gambling Reform Bill (2012) was passed by the Parliament of the Commonwealth of Australia with the objective of reducing harm caused by gaming machines.
} 
disclosure relating to responsible gambling (particularly in terms of public awareness activities regarding harm minimisation) in the annual reports of gambling organisations.

The basis of propositions 1 and 2a is that community and stakeholder support is generally required for corporations to survive in the longer run, and should an organisation's legitimacy be questioned, then stakeholders might switch to other organisations that project values that are more in alignment with community values. At times, however, other pressures will come to light which might act to moderate the focus on attaining community support through social disclosures. In the period of our analysis one potentially important moderating factor was the Global Financial Crisis (GFC).

In 2007 - when the GFC was at its height - corporations found that support from investors and other providers of financial resources became problematic. Arguably, at this point in time, the importance to organisations of stakeholders with command over financial resources became heightened. Consistent with our proposal that Crown and Tabcorp will increase CSD based on community stakeholder pressure via government initiatives, we also propose that in times of particular financial stress, organisations will reduce their emphasis on promoting an image of social responsibility. As the 15-year time frame of this study (1995 to 2009) covers the time in which the GFC occurred (beginning in 2007) the opportunity to examine this proposal arises. Karaibrahimoglu (2010), in a study of corporate social responsibility disclosures in a sample of Fortune 500 companies, reports that in times of financial crisis there is a significant drop in disclosure and in the number and extent of social responsibility projects undertaken. Consistent with this, we propose:

P2b:Following the global financial crisis in 2007, there will be a decrease in the extent of CSD by gambling organisations in their annual reports in 2007 (and 2008).

The third theory we consider in this study is institutional theory which has been used to explain that organisations will adopt similar organisational structures and particular operating practices and/or reporting policies because of what society or powerful stakeholders expect to see in place across a particular organisational field (often referred to as a form of coercive isomorphism (DiMiggio \& Powell, 1983). Further, if all organisations within an industry are subject to similar pressures then they will tend to copy, or 'mimic', what other leading organisations are doing (mimetic isomorphism). Organisations will tend to mimic the disclosures of leading companies, and this might result in an emphasis on particular social or environmental issues, or particular financial issues. In adopting uniform disclosure approaches, organisations provide themselves with a level of legitimacy that would not otherwise be considered if they deviated from 'accepted' organisational forms or policies (DiMaggio \& Powell, 1983). 
In the current study, institutional theory suggests that gambling organisations may be coerced by powerful stakeholders - for example, the community, via the government - into appearing to adopt and maintain particular practices that are thought to provide institutional legitimacy. We anticipate that the gambling companies across the industry, which are under some similar pressures, will seek to generate a perception that they have embraced the issue of problem gambling and have responded to responsible gambling initiatives (such as the development of a responsible gambling code) as recommended by PC1999 and the MCG in the NFPG (such as venue policies for problem gamblers, including staff training in the responsible conduct of gambling - refer to Table 1). While instituting responsible gambling-related activities and programs, gambling organisations will choose to disclose such information within their annual reports in order to make known to the 'community' that they have changed their behaviour and are adopting practices consistent with community expectations. This also conveys the message that the organisation "is acting on collectively valued purposes in a proper and adequate manner” (Meyer \& Rowan, 1991, p.50). As observed by Deegan et al. (2002, p. 340), "changing activities without communicating such changes is considered to be insufficient" ${ }^{15}$. The insights from institutional theory lead to the following proposition:

P3: Through various pressures to conform to institutional norms of disclosure, there will be similarities in the CSD patterns of Australian gambling companies as they react to the various societal pressures being exerted upon them.

In sum, all three theories - legitimacy, stakeholder, and institutional theory - tend to provide a complementary perspective in predicting and potentially explaining the motivation for providing voluntary CSD that would not be as obvious if we were considering only one of these theories. With these insights, we predict that organisations will institute and report on various activities and strategies to meet the (changing) expectations and demands of their powerful stakeholders in order to maintain legitimacy. While studies have found support for these theories in a variety of industries, this study determines whether these theories seem also to be applicable to the gambling industry, where an organisation's products and services can have a potentially harmful effect on its users (Jones et al., 2009).

\section{Research method and organisational overview}

Within the accounting literature, a common method to research information on corporate social and environmental disclosures is through the analysis of annual reports (Guthrie \& Abeysekera, 2006). In

\footnotetext{
${ }^{15}$ Again, we emphasise that there will likely be a moderation in the amount of disclosures focusing on social issues at the time of the GFC. At this point in time it is likely that management will place relatively more focus on financial issues (Karaibrahimoglu, 2010).
} 
this study, we elected to review annual reports for a number of reasons. First as a legally-required, publicly available and readily accessible reporting document (for listed companies), year on year comparisons are made relatively easy (Woodward, 1998; Tilt, 2001). Second, annual reports are a widespread and popular means of communication to stakeholders and have a high level of credibility (Guthrie \& Parker, 1990; Adams, 2004; Raman, 2006). Third, the two selected companies for this study did not produce any separate social and/or environmental (sustainability) reports for the period of analysis (Crown did produce a brief sustainability report in 2008 and 2009; however, the content of the report was also reproduced in the annual report). Fourth, as this study covers a 15 year period from 1995-2009, the ability to locate and extract all corporate communications data (for example, from web-sites) relating to social and environmental issues from the companies' websites was problematic and could potentially result in incomplete data and inconsistent content analysis (Gray et al., 1995b).

The annual reports of Crown and Tabcorp were examined to ascertain if their disclosures appear to reflect or respond to the external pressure exerted upon them through the recommendations of PC1999, the MCG, and its NFPG, and whether there appears to be consistency between the disclosure responses produced by the two organisations. All annual reports released by Crown and Tabcorp from 1995-2009 were obtained via the companies' website and connect $4^{16}$.

\subsection{The two major Australian gambling organisations}

In contrast to many industries, the gambling industry is typically managed through exclusive licences, issued by the respective state/territory gambling regulatory body (for example, the Victorian Commission for Gambling and Liquor Regulation is the body that administers Victoria's gambling licences) which effectively protects the licensed organisations from competition. Nevertheless, the existence of such exclusivity provides regulatory bodies with a mechanism to control and influence gambling organisation's activities and/or disclosures. For example, Crown Limited is obliged under the terms and conditions of its Casino Licence to comply with various requirements, such as the maximum and minimum numbers of gaming tables and EGMs allowed in the Melbourne Casino. Similarly, if the state/territory gambling regulatory body imposed consumer protection-related information disclosure as a licence requirement, gambling organisations would need to disclose such information in order to comply with the licence requirements.

Crown and Tabcorp were selected for this study for a number of reasons. First, both organisations offer wide-ranging forms of gambling products and services, including gaming, wagering, and lottery products; second, the two organisations control substantial market share (e.g., approximately 85\% (\$4 billion) of total Australian casino industry revenue - (IBISWorld, 2012); third, both organisations were listed on the Australian Securities Exchange (ASX) Top 100 in 2010 and being large companies, their

${ }^{16}$ Connect 4 is an electronic database of annual reports for the largest 500 organizations' (by market capitalisation) listed on the Australian Securities Exchange. 
activities and social and environmental performance are more likely to be visible to stakeholder groups (Nobes \& Parker, 1991). While Tatts Group Limited - the next largest member of the Australian gambling industry - was also listed on the ASX Top 100 in 2010, it was excluded from this study because it was only first listed on the ASX in 2005 and annual reports were, therefore, not available for the 15-year period of this study.

\subsubsection{Crown Limited}

Crown Limited is one of Australia's largest entertainment groups, with its core business and investments in the gaming and entertainment sector (http://www.crowncasino.com.au $)$. Crown Limited was originally owned by Crown Casino when it was listed on the ASX in 1994. In 1999, Crown Casino merged with Publishing and Broadcasting Limited (PBL) and became a part of PBL. In May 2007, PBL announced the proposed de-merger of its businesses into two separately listed companies on the ASX: Crown Limited and Consolidated Media Holdings (Annual Report, 2007). Crown assumed ownership of all of the gaming assets previously owned by the PBL. It reported a normalised net profit after tax (before continued operations and non-recurring items) of \$280.7 million for the year ended 30 June 2009 (Annual Report, 2009). In 2009, the latest period of our analysis, Crown publicly noted that it had implemented a new Responsible Gambling Code of Conduct as part of its ongoing commitment to responsible gambling (Annual Report, 2009).

\subsubsection{Tabcorp Holdings Limited}

According to the company's website, Tabcorp is Australia's 'premier gambling and entertainment group’. Tabcorp’s leading customer brands include Star City and Jupiters Casinos, Tabaret, keno, Luxbet, and TAB Sportsbet. Tabcorp was listed on the ASX in 1994, and employs approximately 11,000 staff nationally in its three major business units: casinos, wagering, and gaming (Annual Report, 2009). Tabcorp reported a net profit after tax (normalised and before non-recurring items) of \$496.2 million for the year ended 30 June 2009 (Annual Report, 2009). In June 2011, Tabcorp demerged its casinos operations which resulted in Tabcorp's casinos business being separately listed as Echo Entertainment Group Limited (ASX: EGP). The existing wagering, gaming, keno and media businesses were retained by Tabcorp (ASX: TAH).

\subsection{Content analysis}

Content analysis was adopted as a research method from which replicable and valid inferences from data to context could be made (Krippendorff, 1980). We utilised the content analysis instrument used by Hackston and Milne (1996) and Deegan et al., (2002), with some adaptation. The content classifications by Hackston and Milne (1996) are based on the earlier schemes developed by Guthrie (1982) and Ernst \& Ernst (1978), which embraced six categories of disclosure, namely: environment, 
energy, human resources, product \& safety, community involvement, and others. In this study, however, an additional broad category - responsible gambling - was added. The reason for the inclusion of the seventh category was that responsible gambling was the primary issue identified in PC1999's recommendations, as well as in the NFPG. Responsible gambling ${ }^{17}$ is defined as "gambling that takes place in a regulated environment where the likelihood for harm is minimal and where people can make informed decisions about their gambling activity” (Queensland Treasury, 2002a, p.3; 2002b, p.4). Within each of these seven broad categories of disclosure identified above, sub-classifications of disclosure are identified (see Appendix A). Additional sub-classifications identified in the review of annual reports were added to several categories: environmental pollution, waste management, water, and recycling were added to the environment category; women in employment, employee training, employee morale, and other human resource issues were added to the human resource category.

Within the responsible gambling category - the category which relates primarily to the work of PC 1999, MCG, and NFPG - we decided to create three sub-categories of disclosure, these being public awareness, responsible environment and support services. The specific disclosure items included under each of these sub-categories are shown in Appendix A. These three sub-categories of disclosure can be related to the contents of Table 1 (and as we have noted earlier, Table 1 summarises the recommendations of PC1999 and the subsequent focus of the NFPG) on the following basis:

- Public awareness includes disclosures related to promoting the nature of gambling products, the potential for harm and the availability of support services and disclosures relating to education, training and research (i.e., this category includes items noted in the first and fourth categories of Table 1).

- Responsible environment includes disclosure items relating to the development of a responsible gambling environment (category two in Table 1) and includes the relationships of industry operators with gambling associations and regulatory authorities in developing codes of practice and strategies to regulate the gambling environment (e.g. through pre-commitment measures and smartcard technologies to limit the amount gambled).

- Support services includes disclosures relating to intervention, counselling and support services (category three in Table 1) developed collaboratively with industry stakeholders (community services, government and non-government organisations) to minimise harm, for example, across regional, rural and remote locations.

The extent of disclosure made in relation to a particular disclosure category/sub-category was measured by the number of words. The number of words has commonly been used in the previous

\footnotetext{
17 There are many definitions of 'responsible gambling'. An early definition of responsible gambling by Dickerson (1998) includes any gambling operators' practices that aim to reduce harm to gamblers. Blaszcnski, Ladouceur, \& Shaffer (2004) include any policy and practice that prevents or reduces harm associated with gambling, and includes consumer protection, awareness, and education intervention, as well as access to treatment.
} 
research on CSD (Guthrie \& Parker, 1990; Gray et al., 1995a; Deegan \& Gordon, 1996; Deegan \& Rankin, 1999; Islam \& Deegan, 2008). Measuring the number of words (in each category) has been found to correlate highly with other measures used in the literature, such as sentences, or percentage of pages dedicated to particular disclosure themes (Hackston \& Milne, 1996). It should be noted here that we are not attempting to measure 'quality' of disclosure. This would require a number of assessments about: what particular stakeholders want or need and whether such demands are being satisfied; available reporting frameworks; the weighting of particular and alternative aspects or foci for reporting; a consideration of the objectivity or verifiability of particular information; and so forth. Rather, we are measuring the 'extent' of disclosure and our assumption is that the greater the extent of the disclosure (that is the greater the number of words dedicated to particular issues) the more the organisation is trying to bring the respective issue or initiative to the attention of the readers ${ }^{18}$.

A typical gambling organisations' annual report usually includes a chairman's report, managing director's report, financial statements, notes to the financial statements, corporate governance report, auditor's report, social and environmental report, shareholder information, and corporate information. The gambling organisations' CSD is predominantly highlighted in a separate section under headings such as community; contribution to the community; caring for communities; environment and employees; community and environment; employees; enriching communities; our people; corporate social responsibility; customer focus; environmental commitment; supporting our people; or responsible gambling.

In capturing the words of disclosure we ultimately decided not to differentiate between positive disclosures and negative disclosures, that is, between those disclosures which prima facie project the organisation in a positive image versus those disclosures that could be construed as providing negative information about the organisation ${ }^{19}$. The rationale for this decision was that organisations might provide information about negative issues or events (which might be in the public arena in any case) to increase the perceived credibility of the organisation and to acknowledge that the organisation accepts an accountability in relation to this particular aspect of corporate performance. Nevertheless, it would be anticipated that any negative disclosures would be coupled with disclosures of a positive aspect which could identify remedial actions being taken, targets for improvement, and so forth ${ }^{20}$. Hence,

\footnotetext{
${ }^{18}$ One of the researchers on this paper was responsible for all the coding. Nevertheless, as a basic check on the reliability of the coding, two years of coding was also undertaken by the other researchers on this paper. The result was that there was only very minor discrepancy in the results, and this discrepancy was discussed and resolved such that we were satisfied the coding instrument was being appropriately applied.

${ }^{19}$ In prior research, 'positive social disclosures' have been defined as disclosures that depict an organisation as operating in harmony with the community and/or environment while 'negative social disclosures' can be defined as disclosures that depict an organisation as operating to the potential detriment of the community and/or natural environment (Deegan and Rankin, 1996).

${ }^{20}$ Indeed, as we will discuss shortly, in the limited number of cases where a negative social or environmental disclosure was made, it was made in terms of signalling that there was an actual or potential issue of concern which has been addressed by the organisation. For example, in a limited number of cases, some of the issues raised in PC 1999 and NFPG were disclosed (which prima facie might be construed as a negative disclosure).
} 
providing negative disclosures about a particular social issue might, as with positive disclosures, be part of the legitimising activities of an organisation as the disclosures would highlight that the organisation is aware of the issue, accepts that it has an accountability or responsibility in relation to the issue, and believes that it is important enough to discuss within the report.

The fifteen-year period of analysis in this study was divided into three phases of equivalent duration that approximated (potentially different) periods of developing external pressures on the gambling industry, related to the timing of government initiatives. The three phases are:

- $\quad$ Phase 1: 1995 to 1999 - before PC 1999;

- $\quad$ Phase 2: 2000 to 2004 - after PC 1999 and the establishment of the MCG;

- $\quad$ Phase 3: 2005 to 2009 - after the introduction of the MCG’s NFPG 2004-2008.

\section{Results}

In examining the nature, content, and extent of CSD by Tabcorp and Crown, annual report disclosures were collated for each organisation by year in total, and by year for each of the seven categories: environment, energy, human resource, product \& safety, community involvement, others, and responsible gambling.

Figure 1 depicts the CSD in total by the two organisations from 1995 to 2009. For both companies, there is a general trend of increasing total CSD over time (at least until 2007 see below for further discussion), with a comparatively low amount of disclosure in the 1995-1999 period (Phase 1), followed by a pronounced upward shift in the 2000-2004 period (Phase 2), and culminating in a peak in disclosures in the 2005-2009 period (Phase 3). On the whole, Crown and Tabcorp have similar trends for disclosures (and similar absolute amounts of disclosure) over the fifteen-year period of analysis which in itself is an interesting finding given the voluntary nature of such disclosures (and which in itself might be an indication of the 'institutionalised' nature of the CSD, albeit that such a judgement is based on a small sample).

\section{Insert Figure 1 here}

In Phase 1 (1995 - 1999), the limited disclosure may reflect a time of liberalisation in the gambling industry, where community attention was drawn to the economic benefits of gambling rather than to its negative social impacts (i.e., the low level of CSD can be related to the relatively limited external [community] pressure being experienced by the gambling industry regarding the social-related issues and costs of gambling).

The increase in the total CSD during Phase 2, particularly in 2000 and 2003, coincided with increased community concerns about the social issues associated with problem gamblers, the

However, they were coupled with a positive 'legitimising' disclosure which either acted to challenge the nature of the concern, or indicated how the company took actions to address the concern. 
subsequent establishment of the MCG in 2000, and development of the NFPG 2004-2008. This finding supports the view that the increase in CSD could be construed as a reactive response by organisations to provide more information about its social and environmental activities in order to maintain legitimacy.

In Phase 3, fluctuations in total CSD can be observed with an increase in disclosures in the initial period followed by a decrease in 2007 (and 2008), and an increase in the last year of analysis (2009). Both companies' CSD reach a peak in this phase which is consistent with our prediction that with the implementation of the NFPG 2004-2008 there would be a commensurate increase in total CSD. A contrary result, however, can be observed in 2007 for both organisations (with Crown also further decreasing in 2008) where the CSD decreased dramatically. This is consistent with our proposition (2b) that the GFC would lead to a subsequent decrease in CSD as corporate managers shifted attention from community and broader 'stakeholder' concerns to shareholders' concerns (that is, a 'shareholder primacy' focus was more actively embraced during the GFC). A review of the two organisations' annual reports for 2007 and 2008 supports this conjecture, with increased annual report disclosures on financial matters and responsible directors' remuneration relative to social and environmental disclosures.

The increased CSD in 2009, particularly apparent for Crown, coincided with a second governmentinitiated public inquiry into the gambling industry, which commenced in November 2008. The aim of this inquiry was to update PC1999 and provide additional research to assess the impacts of harm minimisation measures since 1999. Thus, this latest inquiry could be viewed as another legitimacythreatening event, the response to which was an increase in CSD in 2009. It also occurred at a time when concerns relating to the GFC were reducing to some extent.

Overall, the results showed an increasing trend in CSD which appeared to be associated with increasing external pressure. In addition, we also found that the CSD was predominantly positive and it was rare to find instances of negative disclosure ${ }^{21}$. Such a finding - minimal negative CSD - is similar to the results reported in Jones et al. (2009) - a study of the UK gambling industry wherein the authors found that the overwhelming majority of the social disclosure was positive in nature. The results are also consistent with research appearing in the social accounting literature in which it is suggested that positive disclosures are the most effective means of trying to maintain or restore legitimacy around potentially legitimacy-threatening events (although, as we noted earlier in this paper, there is a counter

\footnotetext{
${ }^{21}$ Positive and negative disclosures were defined earlier in this paper. For example, a positive CSD disclosure would be "Burswood chefs annually prepare more than 9,000 litres of soup, which is donated to Foodbank Western Australia to support Perth's homeless" (Crown Limited, Annual Report 2009)”. A negative CSD disclosure would be "High occupancy rates and high humidity levels at the Jupiters Townsville Hotel and Casino, resulted in a 3\% increase in total greenhouse gas emissions in 2007". In a sense this negative disclosure provides a form of 'excuse' for a rise in emission levels. Further, this disclosure was also coupled with information about how other initiatives will bring down the absolute amount of future greenhouse emissions (Tabcorp Holdings Limited, Annual Report 2007).
} 
argument that the disclosure of negative information might also, in certain circumstances, be beneficial for maintaining or regaining threatened legitimacy) ${ }^{22}$.

From our results, the CSD of the gambling organisations can be construed as appearing to be more for legitimising purposes, rather than for demonstrating accountability. As Gray et al. (1996, p.38) suggest, accountability is "the duty to provide an account (by no means necessarily a financial account) or reckoning of those actions for which one is held accountable”. If gambling organisations are to embrace an 'accountability' to the community, then arguably they would have provided CSD in a manner that represented a balanced and genuine attempt to cover some negative, as well as positive aspects, of their social performance (Adams, 2004) - and this should be regardless of external pressures. However, as we have shown, CSD over the 3 phases appeared to alter and we believe this was a result of the external pressure emanating from the community, via government. The focus on providing social disclosures also seemed to wane around the time of the GFC when corporate survival was, at the time, more likely to be linked to economic or financial factors. If corporations embraced ‘true accountability’ based on such considerations as stakeholders' rights-to-know, then accountability for social issues would not decline when potential survival threats from the GFC arose.

Whilst Figure 1 provides aggregated results for all CSD, Tables 2 and 3 provide a summary of the yearly totals in words over the three phases from 1995 to 2009 for the seven broad categories of disclosure for Crown and Tabcorp, respectively. Consistent with the perspective that organisations within the same industry will tend to respond in a similar manner to various pressures, both Crown and Tabcorp exhibit comparable and similar disclosure trends. Both companies take a similar focus on disclosure categories with the four highest specific categories of CSD being human resources, community involvement, others, and responsible gambling. The extent of environmental and energyrelated disclosures shows an increase during Phase 3. Product \& safety-related disclosure were relatively minimal for both companies over the fifteen years of the study.

\section{Insert Table 2 here}

\section{Insert Table 3 here}

The most highly represented category - human resources - mainly covered issues of employee morale, employee profile, employee training, employment of minorities and women, industrial relations, health and safety, employee assistance/benefits, employee remuneration, and 'other human resource disclosures' (Appendix A identifies the disclosures that are included under the caption 'other human resource disclosures'). Disclosures relating to employee morale, other human resource

\footnotetext{
${ }^{22}$ Whilst it is not something that we pursue in this paper, the almost total lack of negative disclosures in relation to problem gambling is interesting. Though it is conjecture, it might be that organisations consider that because problem gamblers have various potential means of, and venues for, gambling, one particular organisation cannot, and perhaps should not, take responsibility for the negative attributes of problem gambling, though of course it can take initiatives to try to reduce it (education and so forth). Perhaps it is a cost that is more correctly attributed to the industry, rather than at the corporate level and therefore it is more relevant to reporting that is undertaken at a broader industry level.
} 
disclosures, employee profile and employee training are among the highest for Crown; for Tabcorp, employee morale and employee profile are significantly higher compared to other sub-categories. Both companies disclose relatively limited information on minorities and women, employee remuneration, and employee assistance/benefits across the period of study. Health and safety-related disclosures only appear within annual reports in the mid-2000s. It is interesting that the organisations show high levels of disclosure in relation to employees when a great deal of the political and society pressure related to problem gambling. Potentially, the companies are attempting to deflect attention to the assistance or support that they are providing to one stakeholder group (employees) over and above the help being provided to another stakeholder group (problem gamblers) ${ }^{23}$.

The second highest category of disclosure - community involvement - covers issues of donations and support for community activities, community health projects, sports projects, and education projects. Company disclosures tended to emphasis positive aspects associated with donations to community, charitable, or not-for-profit organisations. Again, there was a general trend of increasing disclosures here (until 2007) and this could also be evidence of the organisations attempting to deflect attention away from the critical issue of problem gambling. Interestingly, this was one category of disclosure that dropped dramatically in 2007 and 2008 (rebounding somewhat in 2009). Whilst conjecture, the reason for this might be that immediately following the GFC, particularly powerful stakeholders at the time (for example, shareholders) would not want to hear about the company transferring financial resources away from the company and towards projects that were not directly income producing.

The third highest category - other social and environmental disclosure - included 'general' issues such as corporate objectives/policies, corporate governance practices, and those related to 'customer focus' such as improving customer satisfaction, customer loyalty, and survey results on customer issues. An increasing emphasis on customers (i.e., gamblers) was observed in the annual reports of both companies and is of particular interest given that customers represent a potentially powerful industry stakeholder.

The responsible gambling category accounts for the fourth highest proportion of CSD. As this category is one that differentiates the CSDs of gambling organisations from organisations in other industries, and because it is the category of disclosure which closely relates to the pressures being exerted on the industry, a detailed discussion of this category and its sub-categories (public awareness, responsible environment, and support services) will be provided shortly (refer also to Table 4 and Table 5).

During Phase 1, only 5 categories of CSD were provided by both companies, these being human resource, community involvement, others, product \& safety, and responsible gambling. No disclosures

\footnotetext{
${ }^{23}$ As noted previously in this paper, one of the legitimising strategies that organisations can take when their legitimacy appears threatened is to use disclosures to deflect (distract) attention from potentially negative aspects of performance to different, but positive, performance attributes (Lindblom, 1993).
} 
were made within the environmental and energy category, and there was very limited disclosure within the responsible gambling category. Tabcorp made no disclosure on responsible gambling before 1999 (and therefore before PC1999), and disclosures in 1999 were limited to twelve words. Crown provides limited disclosure of responsible gambling issues from 1996 to 1998 (379 words) but no disclosure in 1995 or 1999. The absence of disclosure in 1999 may be linked to a change of ownership from Crown Casino to PBL in 1999 with a shift in the focus of CSD practices.

During Phase 2, the focus of increasing CSD by both companies remained on the human resources, community involvement, and other social and environmental disclosure categories. Disclosures in these categories typically revolved around philanthropy and corporate citizenship, charity donations, sponsorship to local community and sporting organisations. These results are generally consistent with those of Jones et al. (2009), who found that the UK gambling companies increased disclosures of information related to their charitable donations and contribution to the communities in periods when they were under sustained political scrutiny in relation to such issues as problem gambling. Such strategies are aimed at fostering a positive image of the gambling companies at a time when other factors may be undermining their image (O’Donovan, 2002; Deegan et al., 2002).

Of particular interest in this second phase was the considerable attention of management to the responsible gambling category; total disclosures by Tabcorp increased from 12 words in Phase 1 to 1693 words in Phase 2. This appeared to be a rather dramatic increase, and whilst we cannot be certain that it was a reaction to the government initiatives, it is certainly consistent with the organisations adopting a tactic of producing legitimising disclosures in response to the government scrutiny that was in place. For the first time in the history of annual reports for Tabcorp, a sub-section heading was devoted to Responsible Gambling. This sub-section included details of responsible gambling and harm minimisation initiatives adopted by the company such as display materials about the availability of problem gambling counselling service, and about a self-exclusion program ${ }^{24}$, and the launch of Tabcorp's Responsible Gambling Code. Consistent with our first proposition, increasing disclosures in the responsible gambling category coincide with the recommendations of PC1999, the formation of the MCG in 2000, and development of the NFPG in 2000-2003. In a sense these disclosures were arguably a reaction to the threat of government intervention, the view possibly being that if the companies could show that they are taking the issue seriously then this might reduce the community's perception that some form of government intervention was necessary.

Both companies also commenced disclosing information related to the environmental and energy categories. Disclosures in the environmental category were introduced by both companies in 2001; however, only Tabcorp consistently disclosed in this category in the following years. Tabcorp also

\footnotetext{
${ }^{24}$ An exclusion/self-exclusion program refers to a situation where problem gamblers seek to control their gambling by excluding themselves from gambling venues. Jurisdictions in Australia also allow licensee/gambling organisations to exclude problem gamblers if their gambling is perceived to be damaging to themselves or their dependents (Productivity Commission, 2010)
} 
introduced disclosures in the energy category in 2001, while Crown only introduced energy disclosures in 2004. Even though they are not issues considered in PC1999 or by the MCG, one interpretation of the reason for this disclosure is that the positive information offered (for example, the receiving of environmental awards) is a way to offset the potentially negative perceptions of gambling companies ${ }^{25}$.

The last phase of our analysis - Phase 3 (2005 to 2009) - shows a shift in focus of CSD. Both organisations continued with relatively high levels of disclosure regarding their community involvement and human resource activities. Crown, however, appears to have chosen to make stakeholders more aware of their environmental activities. The environment category, which was only introduced by Crown in Phase 2 with very limited disclosure, became the third highest disclosure category in Phase 3. While the increased disclosure is arguably a strategy to project a positive company image and deflect attention from issues of problem gambling, an alternative explanation for the increase may also be the introduction of various government initiatives and legislation, together with various reporting guidelines throughout the mid to late 2000s, that tended to have a flow-on effect across all larger organisations $^{26}$. Comparatively, Tabcorp chose to disclose more about responsible gambling, so much so that it became the second highest category of disclosure.

Another interesting finding related to the product \& safety category. We observed very limited disclosure in this category for both companies, although product \& safety-related information was recommended by the PC1999 (for example, basic consumer information such as product price information to players, understanding the nature of the game, and information on the risk of problem gambling - refer to Table 1). Although Crown disclosed product \& safety information from 2000 to 2006, the disclosure was related to its media products (such as magazines) rather than to its gambling products. When PBL de-merged into Crown and CMH in 2007 (Crown was a part of PBL from 1999 to 2006), Crown discontinued disclosure on product \& safety from 2007 to 2009 (also for 1998 and 1999). This trend is similar to Tabcorp where the disclosure of the product \& safety information was minimal and limited to only certain years throughout the period of this study. Further, information provided under this category was related to product development (such as introducing new machines) instead of product safety-related information (such as safety standards demanded by community). The very limited disclosure of this category is somewhat odd given that gambling products and services are potentially harmful to users and a threat to organisational legitimacy.

\footnotetext{
25 Alternatively, across this period there was also a general increase in community concern about the environmental performance of organisations, inclusive of organisational contribution to climate change, and some of these disclosures could have been in response to such pressures.

26 For example, the National Greenhouse and Energy Reporting Act (2007) and the Energy Efficiency Opportunities Act (2006) were introduced during this period. Whilst such legislation applies to large scale emitters, there would arguably be reporting flow-on effects to other large companies that fall below the required emission thresholds. Also, during the period the uptake of companies to initiatives such as the Carbon Disclosure Project (initially formed in 2000) and the Greenhouse Gas Protocol (an accounting tool for measuring greenhouse gas emissions) increased, all of which provides general impetus (and institutionalised pressure) across corporations to increase the level of environmental reporting.
} 
The extent of disclosure on responsible gambling for Crown and Tabcorp during Phase 2 and 3 are significantly higher than in Phase 1. These results support our first proposition that there will be an increase in the extent of CSD in the annual reports by gambling organisations (particularly in the responsible gambling category) following PC1999. What is also of interest is the nature of the disclosures within the responsible gambling category.

A detailed analysis of disclosure in the responsible gambling category for Crown and Tabcorp is presented in Tables 4 and 5, respectively, and includes the sub-categories of public awareness, responsible environment and support services.

\section{Insert Table 4 here \\ Insert Table 5 here}

The public awareness sub-category disclosures were the highest of all sub-categories and account for more than $70 \%$ of the total amount of responsible gambling disclosures for both companies across the period of our study. Public awareness disclosure includes the promotion of information about the establishment of responsible gambling's codes of conduct, harm minimisation initiatives/programs, counselling services and educational awareness activities and campaigns (including staff training) to raise awareness of responsible gambling. Disclosures in this sub-category increased substantially from 2004 to 2009. We interpret this level of disclosure as being a proactive response by Crown and Tabcorp to the introduction of the NFPG 2004-2008. As an example of related disclosures we can consider the following excerpts from Crown and Tabcorp annual reports:

A high priority is placed on employee training in the areas of responsible gaming and casino awareness. Online training tools are used to raise awareness of core issues and responsibilities. (Crown Limited, Annual Report 2006)

Tabcorp recognises the importance of responsible gambling for the long term sustainability of our industry. For the second year in a row, the Dow Jones Sustainability Index recognised Tabcorp as a global leader in the promotion of responsible gambling. Our commitment to leadership in this area continues and we will work with regulators to maintain the highest standards of care and probity. (Tabcorp Holdings Limited, Annual Report 2009)

The public awareness disclosures could be construed as an attempt to encourage the public to believe that the gambling business operations are taking responsible gambling seriously and in a way that is sympathetic to community expectations. Whilst we can never be certain about the motivations underlying particular disclosures, the focus on positive disclosures pertaining to efforts to reduce the harm of problem gambling does appear consistent with organisations adopting legitimising disclosures around the time that the particular issue was of significant community concern. The disclosures could act as a strategy to prevent or impede the potential introduction of (further) onerous government policies/regulations into the gambling industry that might, in turn, have negative implications for the profitability of gambling companies. For example, in response to stakeholders' concerns reflected in 
the MCG's NFPG, Crown provides additional information on employee training in the areas of responsible gambling in their annual report in 2004 (this information was not available in the 2003 annual report or earlier reports). Only from 2004 did Tabcorp specifically highlight their commitment to promote customer awareness and education through responsible gambling campaigns, employee training in responsible gambling, and professional assistance to customers who require the services.

The second sub-category of disclosures - responsible environment - had relatively limited disclosure representing $10 \%$ and $24 \%$ of the total disclosures in the responsible gambling category by Tabcorp and Crown, respectively. Responsible environment disclosure includes information about an organisation's collaborations with, and/or contributions to, gambling related associations or government authorities to develop strategies, codes of practice and conduct to minimise problem gambling. It also includes information about initiatives undertaken by the organisation 'in house' to foster an environment to reduce the potential harm caused by problem gambling (for example, providing gamblers with personal reports about their gambling expenditure, instituting self-exclusion programs, reducing hours of operation, increased use of natural lighting and visible clocks, introduction of pre-commitment strategies, and limited acceptance of gamblers' cheques). Information about these activities and collaborations, contributions, or affiliations present a positive image that gambling companies are supporting efforts to address problem gambling. Through their disclosures, both gambling companies appear to acknowledge the importance of relationships with stakeholders such as government and/or not-for-profit organisations. As an example of a disclosure in this sub-category we can consider the following excerpt from Tabcorp's annual report:

Tabcorp has taken a leading role in developing the Australian Gaming Council's Framework for Responsible Gaming, which provides a model of best practice for the gaming industry (Tabcorp Holdings Limited, Annual Report 2001).

Support services - another sub-category of responsible gambling, has very limited disclosure, especially during Phase 1 and 2, but attracted some attention during Phase 3 (in the most recent annual reports) for both companies. This category includes issues related to how organisations were engaged in collaborative partnerships to develop effective and accessible counselling and support services across a range of diverse and geographically dispersed communities with a view to minimising harm. As an example of related disclosures we can consider the following excerpt from Crown's annual report:

A program of engagement with a wide range of community service organisations and responsible gaming groups to develop effective support system was also embarked upon throughout the year (Crown Limited, Annual Report 2009).

The analysis above supports our proposition 2a that following the release of the MCG's NFPG 2004-2008, there will be a further increase (over and above that caused by the PC1999) in the extent of disclosure relating to responsible gambling (particularly in terms of disclosures promoting public 
awareness of harm minimisation initiatives) in the annual reports of gambling organisations. Whilst not extensive, the disclosures in the responsible gambling category tended to increase across the period of analysis, particularly since 1999. Minor increases are evident around the time that government initiatives occurred - again suggesting disclosure for legitimation purposes. The results also suggest that there is a potential institutional effect (i.e., gambling organisations tend to be disclosing similar information about operating activities and policies, such as providing information about the implementation of staff training in harm minimisation, and about the introduction of responsible gambling codes). This supports our third proposition that, through various pressures to conform to institutional norms of disclosure, there will be similarities in the CSD patterns of Australian gambling companies as they react to the various societal pressures being exerted upon them.

\section{Discussion and concluding comments}

The aim of this study was to examine the extent and type of CSD within the annual reports of two major Australian gambling organisations over a 15-year period from 1995 to 2009 and to provide some insights into what might be motivating the CSD disclosures. This examination was undertaken within the context of three major contemporaneous Australian government initiatives relating to the gambling industry. To the best of our knowledge, this is the first study to undertake an analysis of the CSD of organisations operating within the Australian gambling industry. We believe our study is particularly timely given the many political issues that continue to be raised in the Australian Federal Parliament (typically by politicians that are independent of the major political parties) about the need for harm minimisation strategies to minimise problem gambling-related social issues. Indeed, in November 2012 the Federal Government passed the National Gambling Reform Bill (2012), which at least in some peoples' minds, is a precursor to further, more stringent, legislation in future years. Also, from a purely descriptive perspective, our research shows how two major Australian gambling companies are disclosing social information - something that, to our knowledge, was not previously reported, and which might now encourage further attention from other researchers.

Our findings show that both Tabcorp and Crown increased CSD over the 15-year period between 1995 - 2009, particularly in the areas of human resources, community involvement, others (customers), and more recently, responsible gambling, and the environment. The increasing levels of disclosure coincide with evolving major government initiatives in the industry, initiatives which are arguably a manifestation of community pressure i.e., Tabcorp and Crown appear to be reacting to increasing community concerns about problem gambling. Whilst the community and government pressure related primarily to problem gambling, our results showed that CSD increased across a variety of social responsibility-related issues other than just problem gambling. We surmise that this is potentially part of a corporate strategy to deflect attention away from problem gambling - which was the major focus of the inquiries and the related submissions - and towards other social issues with which the companies 
could be favourably portrayed. As the disclosures seemed to increase across the same period in which government scrutiny of gambling was increasing, and because of the predominantly positive nature of the disclosures, we believe the disclosures have little to do with demonstrating accountability, but more to do with securing corporate legitimacy. However, the overwhelmingly positive nature of the disclosures could also have the effect of decreasing the credibility of other voluntarily produced information appearing in the annual report - although this is not an issue we have pursued further within this paper. The predominantly positive CSD would seem to be somewhat at odds with the perceived (by certain politicians, NGOs, and the community) seriousness of the issue of problem gambling $^{27}$. The failure of the gambling companies to provide more disclosures pertaining to problem gambling-related harm minimisation might provide more impetus for calls that gambling companies are not taking the problem seriously enough thereby necessitating further government intervention. That is, there appeared to be no clear attempt to 'account' for the actual or potential social 'costs' associated with the organisations' activities.

We find support for all propositions developed in this paper and the explanative power of the three overlapping theories underlying these propositions, these being legitimacy, stakeholder, and institutional theory. This leads us to conclude that in an endeavour to maintain social legitimacy, both Crown and Tabcorp will continue to increase relatively similar and positively-orientated social disclosures in response to powerful stakeholders (in this case the broader community via government) and in order to mitigate any mooted changes in regulations that may impact unfavourably on their operations and profit. Disclosures appear to be motivated by a perceived need to manage their societal level of legitimacy rather than from direct efforts to be accountable to a broad range of stakeholders (Chen and Roberts 2010). A possible, and potentially only short-term, exception to this prediction is when either or both organisation(s) is (are) facing extraordinarily high financial stress (such as from the GFC), at which point we would expect that the corporate annual report disclosures would reorient to matters of financial concern to appease shareholders and other financial capital providers (which in a time of financial crisis might be particularly important in terms of ensuring their ongoing financial support and the firms' survival). In times of financial stress (such as in the GFC) we observe shifts in the perceived power of a particular stakeholder group. However, after securing shareholder and investor support, we would predict that disclosures would shift back to matters of broader societal concern particularly if concerns about issues like problem gambling abound. Future research might investigate further these predictions of positive and increased corporate disclosure (and potentially observe shifts in, or emphasis on, the underlying theoretical foundations) in the light of the Gambling Productivity Commission Inquiry Report 2010 (PC2010) and in years subsequent to the GFC. We

\footnotetext{
${ }^{27}$ As we have indicated elsewhere in this paper, in the very limited number of instances in which otherwise negative CSDs were made they either effectively created a segue for the organisation to discuss initiatives being undertaken to address the issue, or they were followed by disclosures that tried to justify, or provide an excuse, for the otherwise negative information. Apart from such instances of 'negative' disclosure the balance of the CSD was positive in nature.
} 
would surmise that, based on our 15-year analysis, unless significantly greater societal pressure is placed upon gambling organisations and/or evidence is provided that the social costs of problem gambling have decreased, similar disclosures trends to those reported in this study will be found.

Having reviewed the government inquiry report into problem gambling and the respective annual reports, what was clear is that there will obviously always be tensions between an organisation owned by shareholders who traditionally seek sound dividend returns, and the expectations of other stakeholders who seek their interests and expectations to be satisfied. Such tensions will be amplified for an industry such as gambling, which by its nature can create many adverse social impacts. Further, whilst the government needs to appear to be reacting to community concerns (else perhaps risk losing some electoral support), the reality is that government(s) receives a great deal of revenue from the gambling industry and without such revenue many other community-based programs might be abandoned, and/or the taxes imposed on other parts of the community might be increased (which could also create adverse shifts in community, and electoral, support). Whilst we do not pursue these issues in this paper, in terms of further research, the way government might elect to 'play-off' the benefits of gambling (tax revenue to government, employment opportunities, donations to sporting clubs) against the costs of gambling (that is, the various costs associated with problem gambling, some of which will be addressed through government funding) when developing legislation is interesting. Certainly, the debate on implementing various harm minimisation strategies will be continued in 2014 and beyond in view of its complexity involving social, economic and political interests. Clearly there will be different and sometimes conflicting perspectives of the responsibilities and accountabilities of gambling companies, and there will be various and alternative vested interests. A further area for potential research that follows from this is to examine the nature and type of submissions made to the government inquiries into gambling (e.g. PC2010), subsequent government reforms, and the disclosure responses by gambling organisations.

More recently, and as indicated elsewhere in this paper, in November 2012 the Federal Government passed the National Gambling Reform Bill (2012). Whilst this legislation does provide some measures to address problem gambling, there were sentiments from a number of federal politicians that the Bill that was introduced to parliament did not go far enough. As The Age reported (by Lisa Martin, 31 October, 2012):

Greens senator Richard Di Natale said the reform was a "small step ... but a long way from where we need to be". Independent Senator Andrew Wilkie said the reforms were "better than nothing".

"I have no doubt that history will record the limited reforms of this parliament as being the start of the clean-up of an industry that has grown fat on the misery of Australia's most vulnerable people," Mr Wilkie said.

Fellow independent anti-gambling campaigner Nick Xenophon said the only nice thing that could be said about the legislation was that it set a precedent for federal intervention in gambling reform. 
"Unfortunately the reform that has been achieved is $p^{* *}$ s-weak and I blame the government for that," he told AAP. "The fact the pokies industry is relaxed and comfortable about this indicates what a missed opportunity this is."

Therefore, further research could also address the reactions of gambling companies to the recently passed Bill. If this legislation is deemed by the management of the gambling providers to represent a culmination of recent government scrutiny of the gambling industry then this might reduce the perceived need of companies to provide social disclosures to bolster (legitimise) the reputation of the industry. Such disclosures - if driven by legitimation-related intents - may thereafter fall. However, and considering the quotes provided above, if there is still disquiet amongst politicians and if the legislation is a "precedent for (further) federal intervention in gambling reform" then further legitimising disclosures might be deemed necessary for the foreseeable future. In this scenario, social disclosures would not fall.

The above speculation, plus the findings of our research, has implications for the possible regulation of corporate disclosures by companies within the gambling industry. That is, our evidence suggests that CSD will be influenced by the threats to the apparent legitimacy of the organisation, the implication being that if no threats exist, then little CSD disclosure might be made. Consistent with this, our results show that prior to PC1999 there was relatively little CSD by our sample companies. This is despite the fact that problem gambling is not a new problem, but rather is a problem that would, to some extent, have always been associated with the gambling industry. What is 'new' is the level of public and political concern and the consequential need to undertake legitimising activities. In relation to disclosures that seem to be driven by concerns about corporate legitimacy, Deegan, Rankin and Tobin (2002, p.335) note:

Legitimising disclosures are linked to corporate survival. In jurisdictions such as Australia, where there are limited regulatory requirements to provide social and environmental information, management appear to provide information when they are coerced into doing so. Conversely, where there is limited concern, there will be limited disclosures. The evidence in this paper, and elsewhere, suggests that higher levels of disclosure will only occur when community concerns are aroused, or alternatively, until such time that specific regulation is introduced to eliminate managements' disclosure discretion. However, if corporate legitimising activities are successful then perhaps public pressure for government to introduce disclosure legislation will be low and managers will be able to retain control of their social and environmental reporting practices.

We believe that we have provided evidence consistent with the view that disclosures 'wax and wane' selectively as different social and political pressures are exerted on the companies and the industry. Given such pressures are always likely to be at play in the gambling industry, and if we were to embrace a normative position that gambling providers have an obligation to be accountable for the social consequences of their operations and to provide a certain base-line of disclosures (to be determined), then an argument for legislation arises. The costs and benefits of such regulation, and the 
form and type of such disclosures would be an interesting area for research. Such research might consider the 'best' media for gambling companies to fulfil their accountability in relation to corporate social responsibilities. The appropriate vehicle for mandating increased reporting could also be explored in future research. Perhaps our results provide further impetus for calls for the federal government to include CSD requirements within the Corporations $\mathrm{Act}^{28}$. Alternatively, various statebased regulations relating to gambling might be amended to include public disclosure requirements.

We have elected to review annual reports, for the reasons provided in this paper, but obviously there would be other media for disclosure that could be investigated. Also, issues to do with what form of disclosures are most useful in providing or demonstrating appropriate accountability (which in itself requires various judgements to be made about 'to whom' gambling companies are accountable, 'for what' aspects of their operations they are accountable, and 'how' accounts shall be constructed and distributed) provides many interesting areas for research. Also, some consideration might be given to both the appropriateness and the possibilities associated with placing a 'cost' on the social impacts of gambling companies ${ }^{29}$.

In our research we have relied upon secondary data to infer motivations for CSD by Australian gambling organisations. With the benefit of our results relating to actual CSD, future research might usefully utilise interviews with relevant managers from gambling organisations to directly ask them about the motivations for the disclosure.

Such considerations raised above - about conflicting stakeholder demands, government dependence on gambling revenues, implications of new and potential future legislation, and alternative disclosure practices and media - all acts to make this a very interesting area for research. As such, we hope our relatively descriptive research, and the associated discussion, encourages other researchers to further consider the gambling industry as the focus of their accounting research. It is certainly an industry where some accountability seems due, and where ‘accounting' researchers have a role to play.

\footnotetext{
${ }^{28}$ As Deegan and Shelly (2013) explain, in 2005/2006 the Australian Government initiated a public inquiry into the potential introduction of corporate social responsibilities, and associated reporting, into the Australian Corporations Act. There were many submissions in favour, however the government sided with the business community and elected to leave CSR as predominantly voluntary and driven by 'enlightened self-interest'. The government at the time said it could potentially revisit the issue at a future time.

${ }^{29}$ For example, a similar exercise could be contemplated as that undertaken by Bebbington and Gray (2001) in which they undertook an exercise to determine a 'sustainable cost calculation' for Landcare Ltd (New Zealand) a calculation which sought to place a cost on the various negative social consequences of the corporations activities which was then deducted from accounting profits to thereby provide a measure of 'sustainable profit'. Deegan (2014, pp. 462 - 466) provides an overview of some alternative approaches for calculating a 'cost' for the negative externalities created by business organisations.
} 


\section{Appendix A: Organisational Social and Environmental Disclosure Categories in Gambling Industry}

\section{Categories of Social and Environmental Disclosure}

\section{A. Environment}

\section{Environmental Pollution}

- Pollution control in the conduct of the business operations;

- Capital, operating and research and development expenditures for pollution abatement;

- Statements indicating that the organisation's operations are in compliance with environmental laws and regulations;

- Recognition of the need to comply with society standards and regulations;

- Statements indicating that pollution from operations has been or will be reduced;

- Prevention or repair of damage to the environment resulting from processing or natural resources, e.g. land reclamation or reforestation;

- Supporting anti-litter campaigns;

- Receiving an award relating to the company's environmental programmes or policies;

- Disclosing the organisation's involvement in the environmental related organisation memberships;

- Statements supporting the environmental (or environmental friendly) attributes of the operations.

\section{Waste Management}

- Utilising waste materials for energy production;

- Preventing waste;

- Efficiently using materials resources in the manufacturing or operations process;

- Disclosing the organisation's waste management policies;

- Training of employees on waste management;

- Statement indicating the organisation company's waste management procedures.

\section{Water}

- Conservation of water in the conduct of business operations;

- Using water more efficiently during the conduct of business;

- Disclosing the organisation's efforts to reduce water consumption;

- Research aimed at improving water efficiency of business;

- Receiving an award relating to the organisation's water programme or policy;

- Disclosing the organisation's water management policies;

- Disclosing expenditures or purchased of new machinery related to water savings.

\section{Recycling}

- Disclosing energy savings resulting from product recycling;

- Conservation of natural resources, e.g. recycling glass, metals, oil, water and paper;

- Using, or researching, recycled materials;

- Research aimed at improving recycling or related projects or sponsorship;

- Receiving an award or recognition relating to the organisation's recycling programmes or policies;

- Training of employees in relation to recycling;

- Disclosing the organisation's recycling projects or programme;

- Disclosing organisation's savings related to recycling;

- Reporting purchased of new machinery related to company's recycling activities.

\section{Aesthetics}

- Designing facilities harmonious with the environment;

- Contributions in terms of cash or art/sculptures to beautify the environment;

- Restoring historical building/structures.

\section{Other}

- Undertaking environmental impact studies to monitor the organisation's impact on the environmental;

- Conducting reviews of performance, employing specialist consultants; independent auditors or verification related to environmental issues;

- Wildlife conservation. 


\section{B. Energy}

- Conservation of energy in the conduct of business operations;

- Disclosing energy expenditures and using energy more efficiently during the manufacturing process;

- Discussion the organisation's efforts to reduce energy consumption;

- Disclosing increased energy efficiency of products;

- Research aimed at improving energy efficiency of products;

- Receiving an award for an energy conservation programme;

- Voicing the organisation's concern about the energy shortage;

- Disclosing the organisation's energy policies;

- Disclosing purchased of new machinery related to energy savings.

\section{Human Resources}

Health and Safety

- Reducing or eliminating pollutants, irritants, or hazards in the work environment;

- Promoting employee safety and physical or mental health;

- Disclosing accident statistics;

- Disclosing legal non-compliances on health and safety of workers;

- Complying with health and safety standards and regulations;

- Receiving a safety award;

- Establishing a safety department/committee/policy;

- Conducting research to improve work safety;

- Providing low cost health care for employees;

- Compensation. Litigation or enquiries, related to safety;

- Providing information on industrial action related to health and safety;

- Training to employees on health and safety.

\section{Employment of Minorities or Women}

- Recruiting or employment of racial minorities and/or women;

- Disclosing percentage or number of minority and/or women employees in the workforce and/or in the various managerial levels;

- Employment of youth or local community personnel;

- Information on apprenticeship schemes;

- Establishing goals for minority representation in the workforce;

- Programme for the advancement or minorities in the workforce;

- Employment of other special interest groups, e.g. the handicapped, ex-convicts or former drug addicts;

- Disclosures about internal advancement statistics;

- Disclosing or statement of equal opportunity, employee choice, fair treatments, and staff protection related issues such as bullying, harassment.

\section{Employee Training \& Development}

- Training employees through in-house programmes;

- Giving financial assistance to employees in educational institutions or continuing education courses;

- Establishment of trainee centres;

- Disclosing employee career development, career path and promotion related issues.

\section{Employee Assistance/benefits}

- Providing staff accommodation/staff home ownership schemes;

- Providing assistance or guidance to employees who are in the process of retiring or who have been made redundant;

- Providing scholarships for employees' children;

- Providing recreational activities/facilities;

- Disclosing employee leaves and superannuation funds.

\section{Employee Remuneration}

- Providing amount and/or percentage figures for salaries, wages except Directors, executives and senior managements;

- Disclosing workers compensation arrangements except Directors, executives and senior managements;

- Any policies/objectives/reasons for the organisation's remuneration package/schemes except Directors, executives and senior managements;

- Disclosing employee share ownership plan except Directors, executives and senior managements. 


\section{Employee Profiles}

- Providing the number of employees in the organisation and/or at each branch/subsidiary;

- Providing the occupations/managerial levels involved;

- Providing the disposition of staff - where the staff are stationed and the number involved;

- Providing statistics on the number of staff, the length of service in the organisation and their age groups;

- Providing information on the qualifications of employees recruited except Directors, executives and senior managements.

\section{Employee Morale}

- Providing information on the company/management's relationships with the employees in an effort to improve job satisfaction and employee motivation;

- Expressing appreciation or recognition of the employees;

- Seeking employees' opinions and input to planning;

- Providing information on the stability of the workers' jobs and the organisation's future;

- Providing information on the availability of a separate employee report;

- Providing information about any awards for effective communication with employees;

- Providing information about communication with employees on management styles and management programmes which may directly affect the employees;

- Disclosing information on employees' survey statistics or related issues;

- Statement of supporting people or employee engagement

\section{Industrial Relations}

- Reporting on the company's relationship with the trade unions and/or workers;

- Reporting on agreements reached for pay and other conditions.

- Reporting on any strikes, industrial actions/activities and the resultant losses in terms of time and productivity;

- Providing information on how industrial action was reduced / negotiated.

\section{Other}

- Information on the re-organisation of the organisation/discussions/branches which affect the staff in any way;

- The closing down of any part of the organisation, the resultant redundancies created, and any relocation/retraining efforts made by the organisation to retain staff;

- Reporting industrial action associated with a reduction in employees;

- Information and statistics on employee retention and/or employee turnover;

- Reporting or disclosing company receiving industry recognition/ industry awards.

\section{Product and Safety}

\section{Product Development}

- Information on developments related to the products, including its packaging, e.g. making containers reusable;

- The amount/percentage figures of research and development expenditure and/or its benefits;

- Disclosing information or introduction new machines and/or new services;

- Information on research projects or related issues that improve organisation's products or services.

\section{Product Safety}

- Disclosing that products meet applicable safety standards;

- Making products safer for consumers;

- Conducting safety research on products;

- Disclosing improved or more sanitary procedures in the Processing and preparation of products;

- Disclosing legal non-compliances on health and safety of customer;

- Information on the safety of the product and/or disclosing products information.

\section{Product Quality}

- Information on the quality of the products as reflected in prizes/awards received;

- Verifiable information that the quality of the product has increased. 


\section{E. Community Involvement \\ Donation and Community Support}

- Donations of cash, or facilities or products or employee services to support establish community activities, events, organisations and the arts;

- Other special community related activities, e.g. providing civic amenities, supporting town planning;

- Supporting national pride/government sponsored campaigns;

- Recognising local and indigenous communities;

- Providing aid or compensation to communities around their operations;

- Supporting the development or local industries or community programmes and activities;

- Disclosing employees' involvement in the fund raising activities or events;

- Disclosing the organisation's involvement and/or sponsorship in the fund raising events or activities;

- Statements related to the amount raised from fund raising activities or events;

- Disclosing organisation's contributions or community funds and amounts.

\section{Supporting Health Projects}

- Donations of cash or employee services to support health related projects or programmes;

- Sponsoring public health projects or activities or events;

- Providing funding and aiding for medical research;

- Disclosing employees' involvement to support health projects or activities or events.

\section{Supporting Education Projects}

- Sponsoring educational conferences, seminars or art exhibits;

- Donations of cash to educational institutions;

- Funding scholarship programmes or activities or educational funding related issues;

- Statement related to involvement in education related issues.

\section{Supporting Sports Projects}

- Sponsoring sports events or activities;

- Sponsoring national or international sports/games events;

- Disclosing employees' involvement to support sports/games events or programmes.

\section{F. Others}

\section{General issues}

- Corporate objectives/policies: general disclosure of corporate objectives/policies relating to the social responsibility of the company to the various segments of society;

- Disclosing corporate governance practices and/or related to business sustainability;

- Disclosing/reporting to groups in society other than shareholders and employees, e.g. consumers any other information that relates to the social responsibility of the company;

- Statement of being socially responsible in relation to conducting business and/or corporate citizenship;

\section{Customer focus}

- Statements related to improving of customer satisfaction, customer service, customer loyalty, customer centric, and customer focus;

- Research and/or survey on customer related issues.

\section{G. Responsible Gambling}

Public awareness

- Disclosing the organisation's approaches or initiatives or development of programmes related to harm minimisation related issues or strategies;

- Disclosing employees' training related to problem gambling and harm minimisation;

- Disclosing the organisation's code of conducts or amendment to the code of conducts related to harm minimisation or responsible gambling related information;

- Reporting sustainability information or awards or certifications awarded related to harm minimisation;

- Disclosing counselling or related services available to problem gamblers;

- Statement of supporting harm minimisation and/or responsibility gambling;

- Statement of responsible gambling or commitment in responsible gambling;

- Statement indicating leadership in responsible gambling or recognition in responsible gambling;

- Disclosing employment of managers, officers and staff for the responsible gambling purposes;

- Statement indicating establishment of responsible gambling committee 
- Donation of cash or sponsorship to the gambling or problem gambling educational related research, programmes, events or activities;

- Sponsoring gambling related educational awareness activities, campaign and events

\section{Responsible environment}

- Disclosing information about the organisation's collaborations with gambling related associations or organisations or government regulatory authority in developing codes of conduct and/or practice;

- Statements indicating the organisation's membership of gambling associations or organisations in developing codes of conduct and/or practice;

- Disclosing employees' involvement or contribution to the gambling related associations or organisation in developing codes of conduct and/or practice.

- Disclosures relating to initiatives undertaken by the organisation to foster an environment to reduce the potential harm caused by problem gambling (for example, providing gamblers with personal reports about their gambling expenditure, instituting self-exclusion programs, reducing hours of operation, increased use of natural lighting and visible clocks, introduction of pre-commitment strategies, and limited acceptance of gamblers' cheques).

\section{Support services}

- Disclosing the organisation and employees' involvement with stakeholders in relation to gambling related events, support services or activities;

- Statement indicating support and assistance for stakeholder engagement programmes or activities for intervention and support services;

- Reporting information or statistics on stakeholder engagement activities.

Adapted from Hackston and Milne (1996), and Deegan et al. (2002) with changes in italic (only individual items) 


\section{References}

Adams. C. A., 2004, The ethical, social and environmental reporting-performance portrayal gap, Accounting, Auditing \& Accountability Journal 17, 5, 731-757.

Australian Bureau of Statistics, 2008, Taxation Revenue, Australia, 2006/07, Cat. No. 5506.0, Australian Bureau of Statistics, Canberra.

Australasian Gaming Council, Database on Australia’s Gambling Industries 09/10, AGC Home page [Internet document] (Australasian Gaming Council, Melbourne), [cited 5 October 2009], available from http://www.austgamingcouncil.org.au

Australasian Gaming Council, Fact Sheet, AGC Home page [Internet document] (Australasian Gaming Council, Melbourne), [cited 8 October 2009], available from http://www.austgamingcouncil.org.au

Bebbington. J. and R. Gray., 2001, An account of sustainability: failure, success and a reconceptualization, Critical Perspectives on Accounting, 12, 5, 557 - 605.

Blaszczynski, A., R. Ladouceur, and H. Shaffer, 2004, A science-based framework for responsible gambling: The Reno model, Journal of Gambling Studies 20, 3, 301-317.

Brown, N. and C. Deegan, 1998, The public disclosure of environmental performance information - A dual test of media agenda setting theory and legitimacy theory, Accounting and Business Research $29,1,21-41$.

Chen, J.C. and R.W. Roberts, 2010, Toward a more coherent understanding of the organization-society relationship: a theoretical consideration for social and environmental accounting research, Journal of Business Ethics, 97, 651-665.

Crown Limited, Annual Report 1995 to 2009, Crown Limited Home page [Internet document] (Crown Limited, Melbourne, [cited 15 to 30 September 2009], available from http://www.crowncasino.com.au

Deegan, C., 2002, Introduction: the legitimizing effect of social and environmental disclosures: a theoretical foundation, Accounting, Auditing \& Accountability Journal 15, 3, 282-311.

Deegan, C., 2014, Financial Accounting Theory, $4^{\text {th }}$ ed (McGraw Hill Book Company, Sydney).

Deegan, C., 2013, Australian Financial Accounting, $7^{\text {th }}$ eds, (McGraw Hill Book Company, Sydney).

Deegan, C. and C. Blomquist, 2006, Stakeholder influence on corporate reporting: an exploration of the interaction between WWF-Australian and the Australian minerals industry, Accounting, Organizations and Society 31, 343-372.

Deegan, C. and B. Gordon, 1996, A study of the environmental disclosure practices of Australian corporations, Accounting and Business Research 26, 3, 187-199.

Deegan, C. and M. Rankin, 1996, Do Australian companies report environmental news objectively? An analysis of environmental disclosures by firms prosecuted successfully by the environmental protection authority, Accounting, Auditing \& Accountability Journal 9, 2, 50-67.

Deegan, C. and M. Rankin, 1997, The materiality of environmental information to users of annual reports, Accounting, Auditing \& Accountability Journal 10, 4, 562-583.

Deegan, C. and M. Rankin, 1999, The environmental reporting expectations gap: Australian evidence, British Accounting Review 31, 313-346.

Deegan, C., M. Rankin, and J. Tobin, 2002, An examination of the corporate social and environmental disclosures of BHP from 1983-1997: A test of legitimacy theory, Accounting, Auditing \& Accountability Journal 15, 312-343.

Deegan, C. and M. Shelly, 2013, Corporate Social Responsibilities: To Regulate or not to Regulate? Journal of Business Ethics, forthcoming.

Department of Families, Housing, Community Services and Indigenous Affairs, Review of current and future trends in interactive gambling activity and regulation, FaHCSIA Home page [Internet document] (Department of Families, Housing, Community Services and Indigenous Affairs), [cited 18 November 2009], available from http://www.fahcsia.gov.au

Dickerson, M. G., 1998, Gaming machine players and responsible gambling', Paper presented at the National Association for Gambling Studies Practitioners' Conference, Adelaide.

Dillard, J.F., J.T. Rigsby, and C. Goodman, 2004, The making and remaking of organization context: duality and the institutionalization process, Accounting, Auditing \& Accountability Journal 17, 4, 506-542. 
DiMaggio, P. J. and W. W. Powell, 1983, The iron cage revisited-institutional isomorphism and collective rationality in organizational field, American Sociological Review 48, 2, 147-160.

Ernst and Ernst, 1978, Social Responsibility Disclosure, 1978 Survey, Ernst \& Ernst (Cleveland, OH).

Freeman, R., 1984, Strategic Management: A stakeholder Approach, (Pitman, Marshall, MA).

Gambling Research Australia, Ministerial Council on Gambling, GRA Home page [Internet document] (Gambling Research Australia, Australia) [cited 30 September 2009], available from http://www.gamblingresearch.org.au

Gray, R., J. Bebbington, and D. J. Collison, 2006, NGOs, civil society and accountability: making the people accountable to capital, Accounting, Auditing \& Accountability Journal 19, 3, 319-348.

Gray, R., R. Kouhy, and S. Lavers, 1995a, Corporate social and environmental reporting: A review of the literature and a longitudinal study of UK disclosure, Accounting, Auditing \& Accountability Journal 8, 2, 47-77.

Gray, R., R. Kouhy, and S. Lavers, 1995b, Methodologies themes, constructing a research database of social and environmental reporting by UK companies, Accounting, Auditing \& Accountability Journal, 8, 2, 78-101.

Gray, R., D. Owen, and C. Adams, 1996, Accounting and Accountability: Social and Environmental Accounting in A Changing World (Prentice Hall, Hemel Hempstead).

Guthrie, J., 1982, Social accounting in Australia: Social responsibility disclosure in the Top 150 listed Australian companies' annual reports, Unpublished Masters dissertation (West Australian Institute of Technology, Perth, Western Australia).

Guthrie, J. and I. Abeysekera, 2006, Content analysis of social, environmental reporting: What is new?, Journal of Human Resource Costing and Accounting 10, 2, 114-126.

Guthrie, J. and L. D. Parker, 1990, Corporate social disclosure practice: a comparative international analysis, Advances in Public Interest Accounting 3, 159-75.

Hackston, D. and M. Milne, 1996, Some determinants of social and environmental disclosures in New Zealand companies, Accounting, Auditing \& Accountability Journal 9, 1, 77-108.

IBISWorld (2012) Casinos in Australia (P9322), IBISWorld Pty Ltd, viewed 12 October, 2010.

Islam, M. A. and C. Deegan, 2008, Motivations for an organisation within a developing country to report social responsibility information: evidence from Bangladesh, Accounting, Auditing \& Accountability Journal 21, 6, 850-874.

Jones, P., D. Hillier, and D. Comfort, 2009, Corporate social responsibility in the UK gambling industry, Corporate Governance 9, 2, 189-201.

Karaibrahimoglu, Y.Z., 2010, Corporate social responsibility in times of financial crisis, African Journal of Business Management, 4, 4, 382-389.

Krippendorff, K., 1980, Content analysis: an introduction to its methodology (Saga, Beverly Hills, CA).

Lindblom, C., 1993, The implications of organizational legitimacy for corporate social performance \& disclosure, Paper presented at the Critical Perspectives on Accounting Conference, New York.

Mathews, M. R., 1993, Socially Responsible Accounting (Chapman Hall, London).

McWilliams, A. and D. Siegel, 2001, Corporate social responsibility: a theory of the firm perspective, Academy of Management Review 26, 117-127.

Meyer, J.W. and B. Rowan, 1991, Institutionalized organizations: formal structures as myth and ceremony, in Powell, W.W. and P.J. DiMaggio, The New Institutionalism in Organizational Analysis, eds. (University of Chicago Press, Chicago), 41-62.

Milne, M. J. and D. M. Patten, 2002, Securing organizational legitimacy: an experimental decision case examining the impact of environmental disclosures, Accounting, Auditing \& Accountability Journal 15, 372-405.

Neal. P., P. Delfabbro, and M. O’Neill, 2005, Problem gambling and harm: towards a national definition, Report prepared for the National Gambling Research Program Working Party, Melbourne.

Nobes, C. and R. Parker, 1991, Comparative International Accounting, $3^{\text {rd }}$ eds (Prentice Hall, Hamel Hampstead, UK).

O’Donovan, G., 2002, Environmental disclosures in the annual report: extending the applicability and predictive power of legitimacy theory, Accounting, Auditing \& Accountability Journal 15, 3, 344371. 
Patten, D.M., 1992, Intra-industry environmental disclosures in response to the Alaskan oil spill: A note on legitimacy theory, Accounting, Organizations and Society 17, 5, 471-475.

Productivity Commission, 1999, Australia's Gambling Industries, Report No. 10, AusInfo, Commonwealth of Australia, Canberra, December.

Productivity Commission, 2008, Gambling, Issues Paper, Commonwealth of Australia, Canberra, December.

Productivity Commission, 2009, Gambling, Draft Report, Commonwealth of Australia, Canberra, October.

Productivity Commission, 2010, Gambling, Report No. 50, Commonwealth of Australia, Canberra, June.

Queensland Treasury, 2002a, The Queensland responsible gambling strategy: A partnership approach, Queensland Government Treasury (Brisbane, Australia).

Queensland Treasury, 2002b, Queensland responsible gambling code of practice: Trial and review, Queensland Government Treasury (Brisbane, Australia).

Raman, S.R., 2006, Corporate social reporting in India - a view from the top, Global Business Review, 7, 313-324.

Shocker, A. D. and S. P. Sethi, 1974, An approach to incorporating societal preferences in developing corporate action strategies, in Sethi, S., The unstable ground: corporate social policy in a dynamic society (Melvill Publishing Company, Los Angeles, California).

Suchman, M.C., 1995, Managing legitimacy: strategic and institutional approaches, Academy of Management Journal 20, 3, 571-610.

Tabcorp Holdings Limited, Annual Report 1995 to 2009, Tabcorp Holdings Limited Home page [Internet document] (Tabcorp Holdings Limited, Melbourne, [cited 15 to 30 September 2009], available from http://www.tabcorp.com.au

Tilt, C.A., 2001, The content and disclosure of Australian corporate environmental policies, Accounting, Auditing and Accountability Journal, 14, 2, 190-212. 
Table 1: The PC 1999's recommendations and the focus of NFPG 2004-2008

\begin{tabular}{l}
\hline PC 1999's Recommendations \\
\hline 1. Basic consumer information \\
Improving consumer protection through enhancing \\
informational strategies intended to ensure consumers \\
can make choices with informed consent and to reduce \\
the risk of people becoming problem gamblers. These \\
include: \\
- The availability of better information about the \\
price of playing games or betting and the odds of \\
winning; \\
Information about how games work to be made \\
available to patrons of gambling venues so as to \\
improve people's understanding of the nature and \\
risks of the game; \\
Information on the risk of problem gambling be \\
made available at gambling venues in ways that are \\
as visible as signs promoting gambling; \\
Information be available about the extent to which \\
gambling-related revenue is earmarked for \\
problem-gambling, harm minimisation, and \\
community awareness campaigns, and for the \\
funding of problem-gambling related research.
\end{tabular}

NFPG 2004-2008

1. Public awareness, education and training

Promote a greater understanding of the nature of gambling products, the potential for harm, and the availability of help and support. Goal to:

- Build community awareness of problem gambling issues and services;

- Ensure that education and awareness campaigns are cognisant of various populations within the community;

- Ensure gamblers have access to consumer information about the nature of gambling products, for example the chances of winning major prizes;

- Raise awareness of health and social welfare professionals about the benefits of early identification of problem gambling;

- Ensure that relevant gambling industry personnel receive appropriate training in the responsible conduct of gambling;

- Ensure the availability of treatment and support services and venue based services, such as exclusions, are well published and promoted.

\section{Responsible environment}

Create an environment for controlling and improving the gambling environment so as to reduce the harm to problem gamblers, and to minimise the development of problem gambling behaviour. Initiatives could be developed 'in house' or in collaboration with gamblingrelated associations and regulatory authorities. Initiatives could include

- Consumers being provided with a written periodic record of their spending for tracking their expenditure on gambling;

- Identification and active help by venue staff to withdraw gambling services from identified problem gamblers;

- To mandate signage which indicates that any patron may self-exclude, and accompanying pamphlets that explain how self-exclusion works

- Tighter controls on gambling advertising, where it is felt that the information provided by a gambling supplier would have the effect of reinforcing inherently false beliefs about the odds of winning or about the way gambling technologies work;

- Controlling hours of opening from 24 hours a day each day of the week to say, 6 days a week for 18 hours a day;

- Reducing the total quantity of gambling products;

- Limiting the accessibility of minors to gambling;

- To provide clocks and natural lighting at gambling venues in order for problem gamblers to be alert to the passing of time;

- Prohibition on credit and cheque-cashing within gaming areas;

\section{Responsible gambling environments}

To minimise the likelihood of recreational gamblers developing problem gambling behaviours. Aim to:

- Consider any impacts on the community when assessing major expansions of gambling opportunities or the introduction of significant new gambling opportunities;

- Further develop and implement Codes of Practice and/or regulatory frameworks to promote responsible practices by operators, and informed decision making by consumers;

- Encourage availability of appropriate venue based interventions for gamblers;

- Further develop and implement Codes of Practice and/or regulatory frameworks that ensure advertising and promotions do not encourage problem gambling;

- Develop strategies to enable gamblers to limit their expenditure or time spent gambling, for example through pre-commitment measures and appropriate controls over financial transactions. 
- Bill acceptors not be included in the design of EGMs, with any cash dispensers being located outside the gaming area;

- Introduce pre-commitment strategies to limit gamblers' expenditure, or time spent on gambling;

- Limitations on the rate of loss;

- Enforced breaks imposed upon gamblers;

- Pay out larger prizes by cheques in order to avoid gamblers gambling with prize money;

- A longer lapse of time between button pushes;

- Lighting, graphics and sound effects to be modified to reduce 'entertainment' aspects;

- Machine design should aim to maximise informed consent and player control.

\section{Counselling/Treatment}

- Problem gambling agencies routinely to carry out follow-up assessments of clients;

- Needs of people of culturally and linguistically diverse backgrounds to be acknowledged;

- To research approaches for determining how best to deliver problem gambling help services to particular groups in the community for whom mainstream approaches may not be suitable;

- Collection of a National Minimum Data set on clients of problem gambling counselling agencies, using an identical set of definitions across all jurisdictions and an approach that would allow repeat clients to be identified as well as clients who attend more than one counselling services.

- Improved training and consistent accreditation processes for gambling counsellors Australia-wide.

\section{Funding of problem gambling services}

- Funding arrangements for problem gambling counselling, support services, research and public education programs should include compulsory contributions from all organisations that provide gambling services.
3. Intervention, counselling and support service

To enhance problem gambling support and treatment services that are effective, accessible and culturally appropriate

- Maintain a problem gambling support and treatment system, which is available generally, including across regional, rural and remote locations;

- Ensure services are effective for culturally and linguistically diverse populations and indigenous people;

- Introduce standardised problem gambling assessment tools for used by counsellors and community workers;

- Ensure counsellors and community workers have appropriate training;

- Develop national standards for problem gambling treatment and support services.

\section{National research and data collection}

To inform the further development of the national framework.

- Implement and further develop the National Gambling Research Program which is jointly funded by all jurisdictions, to increase understanding of the nature and extent of problem gambling and effective intervention strategies in Australia and provide for a clearing-house for gambling research. 
Table 2: Social and Environmental Disclosure of Crown Limited (in words)

\begin{tabular}{|c|c|c|c|c|c|c|c|c|c|}
\hline Phase & Year & Environment & Energy & $\begin{array}{l}\text { Human } \\
\text { Resource }\end{array}$ & $\begin{array}{c}\text { Product } \\
\& \\
\text { Safety }\end{array}$ & $\begin{array}{l}\text { Community } \\
\text { Involvement }\end{array}$ & Others & $\begin{array}{c}\text { Responsible } \\
\text { Gambling }\end{array}$ & Total \\
\hline \multirow{6}{*}{$\begin{array}{c}\text { Phase } \\
1\end{array}$} & 1995 & 0 & 0 & 417 & 0 & 97 & 239 & 0 & 753 \\
\hline & 1996 & 0 & 0 & 698 & 50 & 253 & 227 & 68 & 1296 \\
\hline & 1997 & 0 & 0 & 875 & 43 & 238 & 126 & 200 & 1482 \\
\hline & 1998 & 0 & 0 & 539 & 0 & 93 & 158 & 111 & 901 \\
\hline & 1999 & 0 & 0 & 385 & 0 & 7 & 19 & 0 & 411 \\
\hline & Total & 0 & 0 & 2,914 & 93 & 688 & 769 & 379 & 4,843 \\
\hline \multirow{6}{*}{$\begin{array}{c}\text { Phase } \\
2\end{array}$} & 2000 & 0 & 0 & 946 & 27 & 798 & 116 & 240 & 2127 \\
\hline & 2001 & 28 & 0 & 1128 & 78 & 845 & 230 & 111 & 2420 \\
\hline & 2002 & 0 & 0 & 760 & 37 & 864 & 248 & 247 & 2156 \\
\hline & 2003 & 0 & 0 & 1280 & 58 & 1020 & 517 & 136 & 3011 \\
\hline & 2004 & 221 & 99 & 1303 & 116 & 1590 & 509 & 220 & 4058 \\
\hline & Total & 249 & 99 & 5,417 & 316 & 5,117 & 1,620 & 954 & 13,772 \\
\hline \multirow{6}{*}{$\begin{array}{l}\text { Phase } \\
3\end{array}$} & 2005 & 414 & 100 & 1833 & 110 & 2061 & 478 & 337 & 5333 \\
\hline & 2006 & 755 & 120 & 1310 & 169 & 2013 & 364 & 354 & 5085 \\
\hline & 2007 & 427 & 75 & 785 & 0 & 587 & 63 & 312 & 2249 \\
\hline & 2008 & 270 & 101 & 347 & 0 & 555 & 25 & 279 & 1577 \\
\hline & 2009 & 460 & 258 & 612 & 0 & 702 & 67 & 305 & 2404 \\
\hline & Total & 2,326 & 654 & 4,887 & 279 & 5,918 & 997 & 1,587 & 16,648 \\
\hline \multicolumn{2}{|c|}{ Grand Total } & 2,575 & 753 & 13,218 & 688 & 11,723 & 3,386 & 2,920 & 35,263 \\
\hline
\end{tabular}


Table 3: Social and Environmental Disclosure of Tabcorp Holdings Limited (in words)

\begin{tabular}{|c|c|c|c|c|c|c|c|c|c|}
\hline Phase & Year & Environment & Energy & $\begin{array}{c}\text { Human } \\
\text { Resource }\end{array}$ & $\begin{array}{c}\text { Product } \\
\& \\
\text { Safety }\end{array}$ & $\begin{array}{l}\text { Community } \\
\text { Involvement }\end{array}$ & Others & $\begin{array}{c}\text { Responsible } \\
\text { Gambling }\end{array}$ & Total \\
\hline \multirow{6}{*}{$\begin{array}{c}\text { Phase } \\
1\end{array}$} & 1995 & 0 & 0 & 66 & 61 & 0 & 60 & 0 & 187 \\
\hline & 1996 & 0 & 0 & 108 & 0 & 149 & 112 & 0 & 369 \\
\hline & 1997 & 0 & 0 & 48 & 74 & 192 & 323 & 0 & 637 \\
\hline & 1998 & 0 & 0 & 71 & 196 & 308 & 237 & 0 & 812 \\
\hline & 1999 & 0 & 0 & 156 & 0 & 357 & 359 & 12 & 884 \\
\hline & Total & $\mathbf{0}$ & $\mathbf{0}$ & 449 & 331 & 1,006 & 1,091 & 12 & 2,889 \\
\hline \multirow{6}{*}{$\begin{array}{l}\text { Phase } \\
2\end{array}$} & 2000 & 0 & 0 & 76 & 39 & 624 & 294 & 85 & 1118 \\
\hline & 2001 & 54 & 89 & 82 & 0 & 594 & 453 & 415 & 1687 \\
\hline & 2002 & 53 & 82 & 430 & 0 & 815 & 237 & 264 & 1881 \\
\hline & 2003 & 149 & 100 & 1587 & 0 & 535 & 583 & 321 & 3275 \\
\hline & 2004 & 102 & 61 & 177 & 51 & 601 & 893 & 608 & 2493 \\
\hline & Total & 358 & 332 & 2,352 & 90 & 3,169 & 2,460 & 1,693 & 10,454 \\
\hline \multirow{6}{*}{$\begin{array}{l}\text { Phase } \\
3\end{array}$} & 2005 & 527 & 263 & 898 & 13 & 887 & 631 & 956 & 4175 \\
\hline & 2006 & 453 & 192 & 1473 & 58 & 867 & 1153 & 1206 & 5402 \\
\hline & 2007 & 375 & 114 & 691 & 0 & 199 & 153 & 629 & 2161 \\
\hline & 2008 & 289 & 233 & 651 & 0 & 201 & 217 & 602 & 2193 \\
\hline & 2009 & 258 & 369 & 806 & 66 & 317 & 217 & 588 & 2621 \\
\hline & Total & 1,902 & 1,171 & 4,519 & 137 & 2,471 & 2,371 & 3,981 & 16,552 \\
\hline \multicolumn{2}{|c|}{ Grand Total } & 2,260 & 1,503 & 7,320 & 558 & 6,646 & 5,922 & 5,686 & 29,895 \\
\hline
\end{tabular}


Table 4: Responsible Gambling Disclosure of Crown Limited (in words)

\begin{tabular}{|c|c|c|c|c|c|}
\hline Phase & Year & $\begin{array}{c}\text { Public } \\
\text { awareness }\end{array}$ & $\begin{array}{l}\text { Responsible } \\
\text { environment }\end{array}$ & $\begin{array}{l}\text { Support } \\
\text { services }\end{array}$ & Total \\
\hline \multirow{6}{*}{ Phase 1} & 1995 & 0 & 0 & 0 & 0 \\
\hline & 1996 & 28 & 40 & 0 & 68 \\
\hline & 1997 & 157 & 43 & 0 & 200 \\
\hline & 1998 & 67 & 44 & 0 & 111 \\
\hline & 1999 & 0 & 0 & 0 & 0 \\
\hline & Total & 252 & 127 & $\mathbf{0}$ & 379 \\
\hline \multirow{6}{*}{ Phase 2} & 2000 & 27 & 213 & 0 & 240 \\
\hline & 2001 & 61 & 50 & 0 & 111 \\
\hline & 2002 & 247 & 0 & 0 & 247 \\
\hline & 2003 & 82 & 54 & 0 & 136 \\
\hline & 2004 & 220 & 0 & 0 & 220 \\
\hline & Total & 637 & 317 & $\mathbf{0}$ & 954 \\
\hline \multirow{6}{*}{ Phase 3} & 2005 & 310 & 27 & 0 & 337 \\
\hline & 2006 & 219 & 121 & 14 & 354 \\
\hline & 2007 & 248 & 50 & 14 & 312 \\
\hline & 2008 & 215 & 56 & 8 & 279 \\
\hline & 2009 & 242 & 0 & 63 & 305 \\
\hline & Total & 1,234 & 254 & 99 & 1,587 \\
\hline \multicolumn{2}{|c|}{ Grand Total } & 2,123 & 698 & 99 & 2,920 \\
\hline
\end{tabular}


Table 5: Responsible Gambling Disclosure of Tabcorp Holdings Limited (in words)

\begin{tabular}{|c|c|c|c|c|c|}
\hline Phase & Year & $\begin{array}{c}\text { Public } \\
\text { awareness }\end{array}$ & $\begin{array}{c}\text { Responsible } \\
\text { environment }\end{array}$ & $\begin{array}{c}\text { Support } \\
\text { services }\end{array}$ & Total \\
\hline \multirow{5}{*}{ Phase 1 } & 1995 & 0 & 0 & 0 & 0 \\
& 1996 & 0 & 0 & 0 & 0 \\
& 1997 & 0 & 0 & 0 & 0 \\
& 1998 & 0 & 0 & 0 & 0 \\
& 1999 & 12 & 0 & 0 & 12 \\
\cline { 2 - 6 } Phase 2 & Total & $\mathbf{1 2}$ & $\mathbf{0}$ & $\mathbf{0}$ & $\mathbf{1 2}$ \\
& 2000 & 85 & 0 & 0 & 85 \\
& 2001 & 291 & 124 & 0 & 415 \\
& 2002 & 192 & 35 & 37 & 264 \\
& 2003 & 321 & 0 & 0 & 321 \\
& 2004 & 560 & 48 & 0 & 608 \\
\cline { 2 - 6 } & Total & $\mathbf{1 , 4 4 9}$ & $\mathbf{2 0 7}$ & $\mathbf{3 7}$ & $\mathbf{1 , 6 9 3}$ \\
\hline \multirow{5}{*}{ Phase 3 } & 2005 & 792 & 133 & 31 & 956 \\
& 2006 & 870 & 232 & 104 & 1206 \\
& 2007 & 539 & 0 & 90 & 629 \\
& 2008 & 521 & 0 & 81 & 602 \\
& 2009 & 460 & 0 & 128 & 588 \\
\hline & Total & $\mathbf{3 , 1 8 2}$ & $\mathbf{3 6 5}$ & $\mathbf{4 3 4}$ & $\mathbf{3 , 8 9 1}$ \\
\hline \multicolumn{7}{|c|}{ Grand Total } & $\mathbf{4 , 6 4 3}$ & $\mathbf{5 7 2}$ & $\mathbf{4 7 1}$ & $\mathbf{5 , 6 8 6}$ \\
\hline
\end{tabular}


Figure 1: Gambling Organisations Annual Report Social and Environmental Disclosure from 1995-2009 (in words)

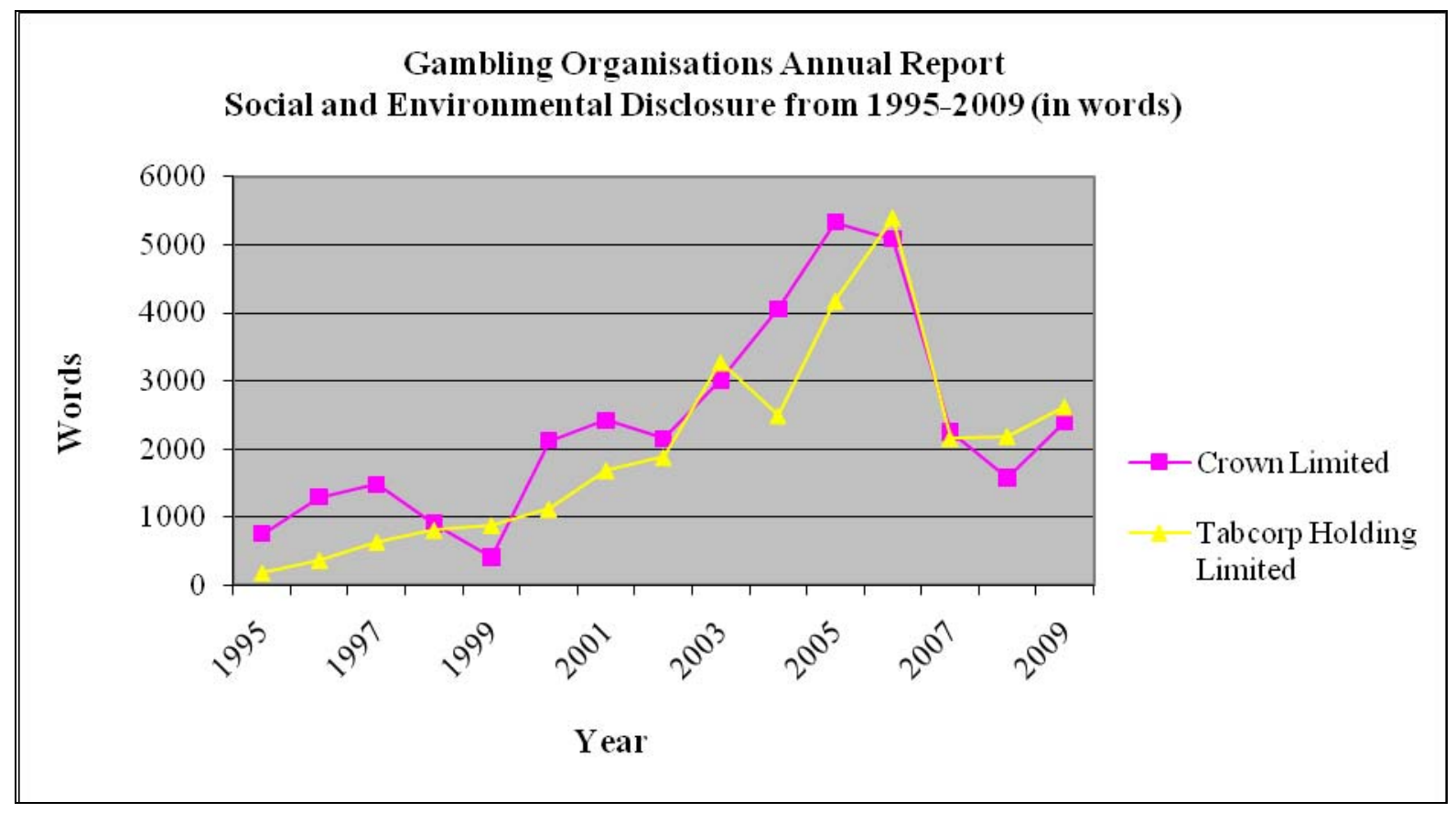

